\title{
A Comparison of Debonding Strengths of Four Metal-Ceramic Systems With and Without Opaque Porcelain
}

Margorie C. Wood

Follow this and additional works at: https://opencommons.uconn.edu/sodm_masters

\section{Recommended Citation}

Wood, Margorie C., "A Comparison of Debonding Strengths of Four Metal-Ceramic Systems With and Without Opaque Porcelain" (2007). SoDM Masters Theses. 157.

https://opencommons.uconn.edu/sodm_masters/157 
A comparison of debonding strengths of four metal-ceramic systems with and without opaque porcelain.

\author{
Marjorie C. Wood
}

D.M.D., University of Pennsylvania, 2002

B.A., University of Vermont, 1993

\author{
A Thesis \\ Submitted in Partial Fulfillment of the \\ Requirements for the Degree of \\ Master of Dental Science \\ at the \\ University of Connecticut \\ 2007
}




\section{APPROVAL PAGE}

\section{Master of Dental Science Thesis}

A Comparison of Debonding Strengths of Four Metal-Ceramic Systems with and without Opaque Porcelain.

Presented by

Marjorie C. Wood, D.M.D.

Major Advisor $\frac{\text { Gokn R Cegar }}{\text { John R. Agar, D.D.S., M.A }}$

Associate Advisor

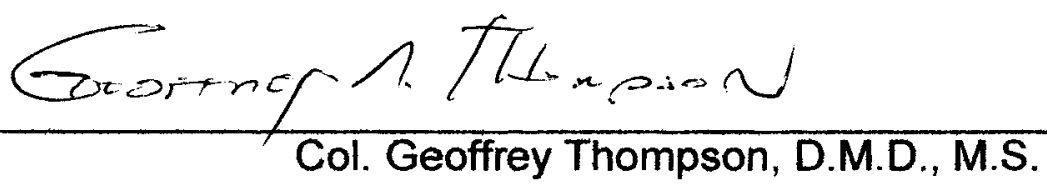

Associate Advisor

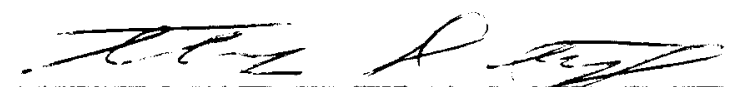

Thomas Taylor, D.D.S., M.S.D

University of Connecticut 


\section{Acknowledgements}

First and foremost I would like to thank my best friend and husband Peter Barndt for his patience with me, and his never-ending help with all things scientific and technical. I

know it's not even close to a repayment, but this Masters Thesis is dedicated to you. I want to be as smart as you are someday.

There are so many people that contributed to the completion of this Masters Thesis. Without a single one of them, it would not be complete. I am forever indebted and grateful to all of you.

Dr. Agar, Thank you for your generosity, time, patience, and diligence. I never would have done this without your persistence and kindness.

Col Thompson, Thank you for your expertise, the use of your magnificent laboratory/ equipment and home, time, and consistent efforts. You make Masters happen.

Dr. Taylor, Thank you for being available and supportive to help fledgling residents like me.

Dr. Rungruanganunt, Thank you for your unwavering friendship and expertise. You have helped me through many difficult times, and not just with this Masters.

My family, Thank you all for your confidence and patience with me when I was frustrated and grumpy during this process. I realize how lucky I am to have your unfailing support and love.

The Laboratory at UConn: Frank, Donna, Denise, Gail, Erik. Thank you for your time and help throughout the three years of residency. I truly know your patience is endless, like Dr. Agar says.

Thank you for all the time and efforts to make this an actual paper: Eileen Chmura and Cindy Phoenix. The many trips all over the Health Center Campus solely for my benefit did not go unnoticed. (Nor did all the faxing of paperwork and letters to Japan.)

Thank you to Dentsply, specifically Tom Cameron and AI MacDonald who provided the alloy specimens and answered many questions at the beginning of this project.

Thank you to the statisticians Dr. Steve Walsh and Mrs. Deb Dauser. I know my ignorance with statistics was trying at times, but you kept helping me despite it.

Thank you to all the UConn residents present during the years 2003 to 2005:

Sangeetha Raghavendra, Elena Nazarova, Peter Barndt, Jin Ha Joung, Sergio Ortegon, Fei Liu, Cornell Lee, Nancy Dubois, Sureeporn Charudilaka, and Carlos Velez. Sorry for all the extra time in the conference room reviewing and helping me with the presentations, variations, and ideas of this Masters... and I didn't even bring food or beer to the defense! 


\section{Table of Contents}

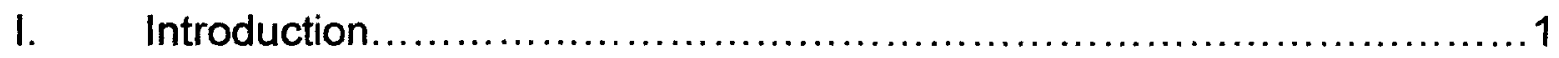

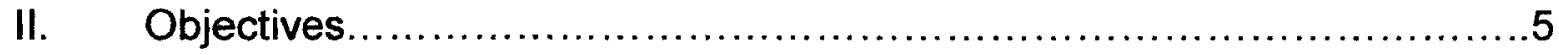

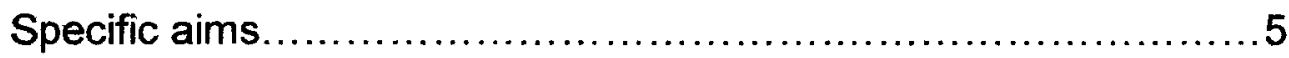

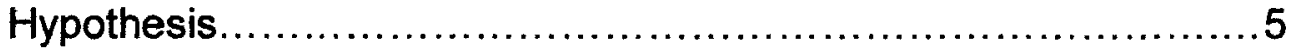

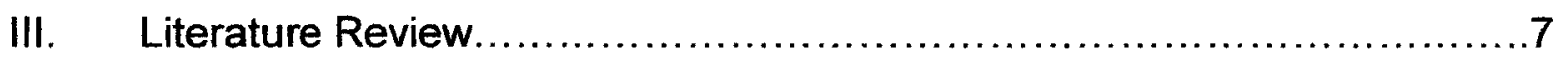

Basic principles................................................

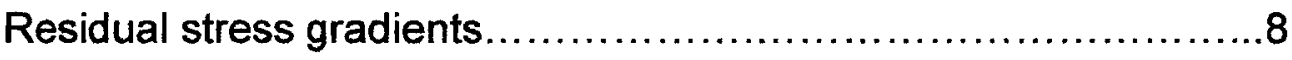

Interfacial chemistry .......................................... 10

Interfacial morphology .........................................

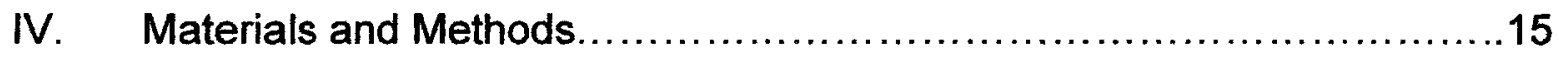

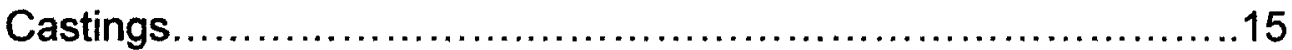

Surface preparation........................................... 15

Surface analysis............................................... 17

Opaque porcelain addition.....................................17

Dentin (Body) porcelain addition...............................19

Bond strength determination ....................................

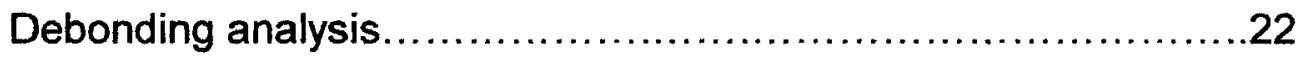

Data analysis................................................22

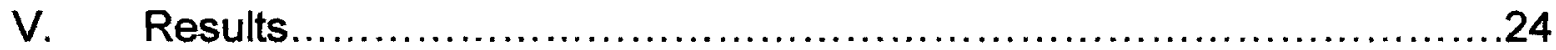

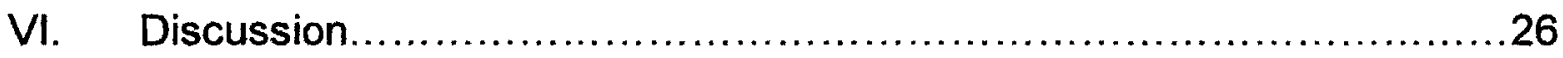

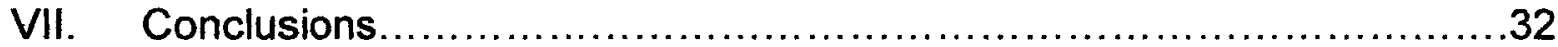

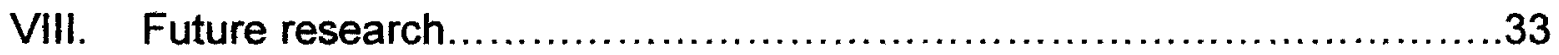

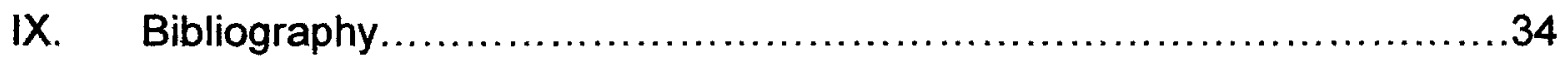

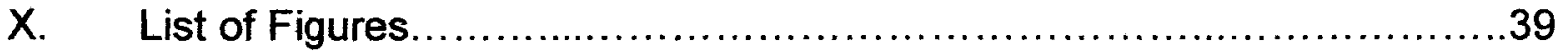

$\mathrm{XI} . \quad$ List of Tables............................................................ 40

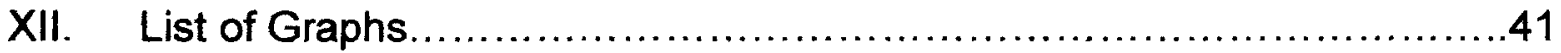

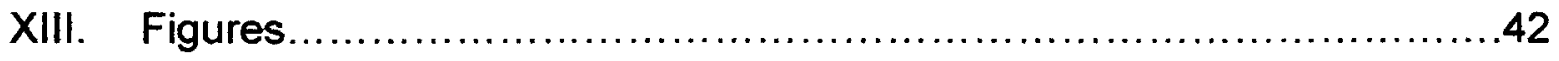

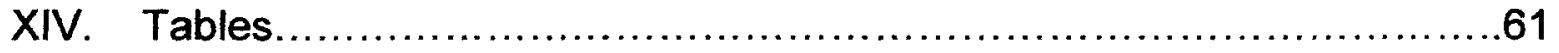

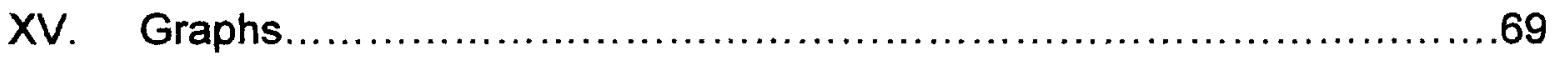




\section{INTRODUCTION}

Despite substantial advances in ceramic core technology, Dentistry continues to see metal copings with porcelain veneers used in crown restorations. The strength of allceramic systems varies considerably and all fall short of metal-ceramic restorations. ${ }^{1,2}$ Metal-ceramic restorations are the standard by which all alternative, esthetic restorations are measured, and continue to be the best choice for anterior fixed partial dentures with limited inter-arch distance. ${ }^{3}$ They are often required for short, tipped and structurally compromised teeth needing auxiliary retention such as grooves, boxes, or pins. ${ }^{2.4}$

In 1956 Brecker and Johnston et al were among the first to describe the dental metal-ceramic restoration with similar technology to that presently in use. Following in 1962, Weinstein patented the metal-ceramic or "porcelain-fused-to-metal" (PFM) restoration. ${ }^{5-7}$ That same year Shell and Nielsen published a paper which described the chemical nature of the porcelain-to-metal bond. ${ }^{8}$ Metal-ceramic bonding theories, in dentistry, found its background in industrial research of the enamel-steel bond, dating back to 1936 in a paper by Kautz entitled "Further data on enamel adherence". ${ }^{9}$ However, even today, the exact bonding mechanisms of metal-ceramics are still not finitely established. Numerous authors credit bonding theories to include chemical, mechanical and van der Waals forces. ${ }^{7,8,10-15}$ Also, a slight mismatch in coefficients of thermal expansion between the porcelain and the alloy is credited with placing the porcelain in compression and thereby raising the porcelain resistance to fracture. ${ }^{16-19}$

Unfired dental porcelain appears to the naked eye as a powder. However, with microscopic aid the powder appears as a "heap of broken glass". ${ }^{20}$ The fundamental components of dental porcelains are quartz, feldspar, kaolin, and metal oxides. ${ }^{13,20,21}$ Regardless of manufacturers' specific formulations, to fabricate dental porcelain these four basic constituent materials are heated together to a high temperature to form a glassy phase, rapidly quenched in cold water, and pulverized into a "frit". This frit is 
milled into what can be used as the many different forms of dental porcelains including opaque, dentin (body), and enamel. The variations in milling (particle size), original raw components, added components, and firing temperatures permit proprietary differences between the many commercially available porcelain systems.

Porcelain used in metal-ceramic restorations has included opaque porcelain, which contains a larger portion of insoluble metal oxides than "body" porcelain." 20 Opaque porcelain is the first ceramic layer added to the alloy substructure. As the name may imply, metal oxides present in opaque porcelain intercept and scatter light transmission and mask the metal substructure color. ${ }^{7,20-22}$ It is assumed that these metal oxides within opaque porcelains are both partly responsible and necessary for the metalceramic bond. ${ }^{5,12,22-24}$ There is considerable discussion in the literature about the oxides of the metal alloy being responsible for the metal ceramic bond, however less attention has focused on the necessity of the corresponding oxides in opaque porcelain. That is, whether or not opaque porcelain is specifically required for the metal-ceramic bond has not been adequately proven. In fact, one study indicates that body porcelains may bond to alloys as well as opaque porcelains bond to alloys. ${ }^{22}$

Excessive, abrasive wear of the mandibular anterior dentition opposing maxillary teeth restored with metal-ceramic restorations is a problem in the clinical practice of fixed prosthodontics. ${ }^{25-31}$ (Figure one). Abrasion of mandibular canines can result in the loss of mutually protected occlusion. Small, worn mandibular incisors are difficult to restore. Wear of these teeth can be accompanied by super-eruption, or alveolar growth and eruption, both of which can further complicate the restoration of these short and narrow teeth. ${ }^{27,30,32}$ In addition, most anterior occlusal configurations do not allow for the design of a maxillary, linguo-occlusal surface in metal. ${ }^{4}$

Where restorative space is limited, it is difficult to arrange metal, opaque, and body porcelain to mechanically sound dimensions. In these situations, during delivery of 
restorations and clinical adjustment, opaque porcelain repeatedly becomes exposed with removal of the thin body porcelain on the lingual surfaces of maxillary anterior teeth. Most situations would require a polish of the adjusted area prior to final insertion of the restorations. Although there is compelling literature ${ }^{33-35}$ which states chair-side porcelain polishing produces a similar, if not better, surface finish of porcelain than glazing, it has yet to be determined if opaque porcelain can be polished to a satisfactory, nondestructive level. Nevertheless it seems unlikely that polishing could be effectively done at all because of the composition of opaque porcelain.

In spite of the inconsistency and difficulty in constructing universally accepted wear tests ${ }^{34,36}$ there is significant research describing increased wear of teeth opposing porcelain-occlusal restorations. ${ }^{25,27,37-39}$ Several authors have stated that exposed opaque porcelain may significantly increase the abrasiveness of a metal-ceramic restoration. ${ }^{22,32}$ Opaque porcelains are not fired to the same vitrification temperatures as body porcelains, and after the opaque firing process, a large percentage of incompletely molten material is present within the opaque porcelain. ${ }^{20}$ In addition, the added oxides, which are crystallized, have a hard surface when exposed. ${ }^{20,22,25}$ Kelly et al, in a review of ceramics in dentistry, report that the size and shape of abrasive features developed on a dental ceramic surface during contact appear critical for determining enamel wear. ${ }^{34}$ This potentially increased abrasiveness of exposed opaque porcelain may be witnessed by clinicians. However, there does not appear to be any supporting evidence, in vitro or in vivo studies, to scientifically support greater wear caused by opaque as compared to body porcelains.

The primary aim of this study was to determine whether there is a significant difference in bond strength between opaque and body porcelains bonded to metal alloys. The question of whether opaque porcelain is truly necessary for an acceptable metal-ceramic bond was asked. The goal was to determine if body porcelain alone can 
be used on the maxillary lingual surfaces of metal-ceramic restorations. The clinical significance is that body porcelain used exclusively on the lingual surfaces of maxillary copings may reduce the excessive, destructive abrasion observed when natural teeth oppose exposed opaque porcelain. 


\section{OBJECTIVES}

The clinical observation of excessively worn teeth opposing over-adjusted, unpolished metal-ceramic restorations is a recurring problem in Prosthodontics. The primary objective of this study was to determine if bond strengths are similar between two different metal alloys and two different ceramic systems with and without the use of opaque porcelain.

\section{Specific Aims}

A. To analyze bonding strength results and to determine if opaque porcelain is necessary for clinically adequate bond strength of porcelain to metal within the four systems used and according to requirements established by ISO 9396:1999 (E) Metal-Ceramic Dental Restorative Systems.

B. To promote further testing, of specific metals and porcelains employed together, to determine if opaque porcelain can be removed and if the system retains adequate metal-ceramic bond strength.

C. To reconcile acoustic measurements in conjunction with load-versus-displacement plots.

D. To analyze surface roughness ( $R a)$ and correlate with porcelain to metal bond strength. 


\section{Hypothesis}

The Null Hypothesis tested was:

There is no significant difference in the debonding strength/crack initiation strength of metal-ceramic flexure bars made with and without opaque porcelain. 


\section{LITERATURE REVIEW}

\section{Basic Principles}

The success of a metal-ceramic restoration depends on the strength of the metal-ceramic bond. The most common mechanical failure of these restorations is porcelain debonding from the metal. ${ }^{13}$ Several important concepts relate to the metalceramic bond. It should be realized that these two materials individually have completely different properties, however are expected to act as a composite when used in dentistry.

The two basic forms of chemical bonding are covalent and ionic. Covalent bonding happens when the valence electrons of two atoms are shared. lonic bonding happens when valence electrons are removed and are attached to another atom creating positive and negative ions that can attract each other.

Ceramics are compounds of metallic and non-metallic elements. ${ }^{15}$ Chemically, metal atoms usually combine their valence electrons with other metal and/or non-metal atoms in what is termed a metallic bond, a form of ionic bonding. Metallic bonding has been referred to as a sea of electrons surrounding positive ions. ${ }^{40}$ "Ceramics, however do not contain a large number of free electrons. Their electrons are either shared covalently with adjacent atoms, or they are transferred from one atom to another to produce an ionic bond. lonic bonds produce ceramic materials of relative stability." ${ }^{15}$ It is this stability (and lack of free electrons) which allows ceramics to be labeled "good insulators" (poor conductors.) Other ceramic properties are brittleness, low fracture toughness, poor plastic deformation, and increased resistance to chemical alteration-all characteristics resulting from a lack of free electrons. Metals on the other hand, transfer thermal energy through their "electron sea" of shared electrons, which are free to travel everywhere in a metallic bond. ${ }^{40}$ The properties of metals, converse to ceramics, are good electrical conductivity, malleability, ductility, and a reaction to chemical modification. In addition, metals can be combined to form compounds called alloys, and 
in doing so, the final properties of the new alloy are changed as compared to the initial, individual constituents. Metallurgists design alloys to enhance certain metal properties and diminish others, aiming to produce a final compound that exhibits desired functional qualities. The metal-ceramic restoration, a combination of both ceramic and metal materials, "combines the esthetic beauty of porcelain and the strength and accurate fit of the cast (alloy) metal substrate. ${ }^{n 41}$

So then, how are these two unlike materials bonded together to act as a composite for use in dentistry? According to Wagner, there are three main factors that determine the success of the ceramic-metal bond: residual stress gradients, interfacial chemistry, and interfacial morphology. ${ }^{42}$ These three factors are interdependent and are difficult to evaluate individually. $8,12,15,24,42,43$

\section{Residual Stress Gradients}

Ceramic powders are bonded to metal alloys by placing them together in a furnace and firing to high temperatures to sinter the porcelain to the alloy. The fired porcelain is influenced not only by the maximum temperature attained but also the predrying time, rate of climb, holding time at the final temperature, and cooling method. $20,44,45$

All materials have a coefficient of thermal expansion. The coefficient of thermal expansion (CTE) is generally defined as the fractional increase in length per unit rise in temperature. The exact definition varies, depending on whether it is specified at a precise temperature (true coefficient of thermal expansion) or over a temperature range (mean coefficient of thermal expansion). Graphically, the former is defined by the slope of a tangent line to the length-temperature plot, while the latter is governed by the slope of the chord between two points on this curve. Considerable variation in the value of a material's CTE may occur according to the definition employed. Usually there is an 
increase in CTE with temperature ${ }^{46}$ It is important to note the terms "thermal expansion" and "thermal contraction" are acceptably interchanged in the dental literature. ${ }^{16}$

Knowledge of CTEs of alloys and porcelains used for PFM restorations is imperative. The CTE of the porcelain/alloy pair should be below the glass transition temperature of the porcelain so that the ceramic does not undergo viscous flow to relieve thermal incompatibility stresses that develop during firing ${ }^{21}$. The gap in temperature from when porcelain is viscous enough to behave as a rigid body, until room temperature, is when the interfacial stress will develop in a metal-ceramic restoration. ${ }^{47}$

Invariably, interfacial stresses will exist after porcelain is fired onto a metal alloy. ${ }^{16-19,41,44,45,48}$ These residual, interfacial stresses caused by two independent CTEs can cause crazing or cracking or complete debonding of the porcelain veneer if not controlled. ${ }^{16-18}$ Residual stress gradients have been the focus of much of the basic research in metal-ceramics. ${ }^{42}$ Stress at the interface between the alloy and the porcelain can be described by Timoshenko's bimaterial stress equation. ${ }^{16}$

$$
\sigma=K \Delta a \Delta T
$$

$\mathrm{K}$, a constant based on geometric factors

$\Delta a$, the difference in thermal expansion coefficients

$\Delta T$, the temperature range through which the metal-ceramic system is cooled.

This equation can be used only as an approximation, as a and the glass transition temperature $(\mathrm{Tg})$ vary with the thermal history of the ceramic. ${ }^{16}$ This formula may be used to initially determine interfacial stress levels.

Relatively high transient and residual stresses may develop in metal-ceramic systems due to differences in thermal contraction coefficients. Transient tensile stresses may cause cracks to form during cooling, but if no cracks develop (which form to 
alleviate stress), the residual stress becomes the principal variable that can enhance or reduce the bond strength of a metal-ceramic system.

It is generally believed the alloy should have a higher CTE than the ceramic (termed positive coefficient mismatch) to produce axial and hoop compressive stress in the porcelain after cooling to room temperature. The radial tensile stresses that develop are assumed to be negligible. Since dental ceramics are much stronger under compression than tension, this residual compressive stress can effectively increase the bond strength. ${ }^{16,17}$

Thermal expansion data from room temperature to above the glass-transition temperature range are important for thermal expansion of the porcelain to be matched to the alloy, so that stress levels in the porcelain veneer will be minimized. ${ }^{44,47}$ Tuccillo and Nielsen asserted that maximum bond strength can only be achieved if "weakening factors such as thermal stresses [are] absent". ${ }^{47}$ Since complete eradication of all thermal stresses is impossible, knowledge of $\mathrm{Tg}$ and a for a dental porcelain is of primary importance for determination of the level of stress introduced at the metalporcelain interface when a restoration is being cooled..$^{44}$ In dental laboratory practice, porcelains used for metal-ceramic restorations are fired several hundred degrees above the glass transition temperature, removed from the furnace and allowed to air-cool at rates approaching $600^{\circ} \mathrm{C} / \mathrm{min}$ through the glass-transition temperature range. ${ }^{44}$ The choice of alloy and ceramic pair should be made with attempts to control both a positive coefficient mismatch and the cooling rates of both the porcelain and alloy.

\section{Interfacial Chemistry}

It is generally believed that there are four types of inter-atomic bonds involved in the junction of ceramic to metal (dental porcelain to metal alloy substructure.) lonic, covalent, metallic, and van der Waals forces form the bonds between oxides in both the 
porcelain and alloy. ${ }^{7,12,15,49,50}$ However the question remains as to how the oxide layer functions in the porcelain-metal bond. ${ }^{49}$

Theories to explain the bonding of dental porcelain to metal alloys have been built largely upon the work carried out in industry, specifically the field of porcelain enameling of steel. The first metal-ceramic bonding theory in literature, the "oxide layer theory", was credited to Kautz in 1936. Yet, according to Mackert "nearly all of the discussion of the mechanism of bonding of dental porcelain to metal in the dental literature is based upon the theories of King et al (1959) and Pask and Fulrath (1962)." ${ }^{\text {49 }}$

Kautz's general, non-dental theory clarified that a layer of oxide, adherent to the metal, is wetted by the porcelain and becomes the transition zone between the metal and glass, and that the layer of metal oxide is considered to be tightly bonded both to the metal and to the porcelain. Thus an intermediate layer is formed which is responsible for the porcelain-metal bond. It was proposed that the layer of ceramic nearest the metal dissolves the oxide on the surface of the metal and that a layer of oxide-saturated glass (ceramic) bonds directly $\mathrm{w} /$ the metal surface. ${ }^{49}$

In 1959, King et al proposed a slight change to Kautz's oxide bonding theory. They renamed it as the "interface saturation theory" and proposed the bond was formed directly between the substrate metal and "a layer of glassy phase comprising a saturated solution of the lowest oxide of the substrate metal." In this theory, the adherence of the original oxide layer to the alloy substrate is deemed irrelevant, because this oxide layer is believed to be completely dissolved during the fusing of the enamel. ${ }^{51}$

Three years later, Pask and Fulrath theorized there is a direct chemical bonding between the porcelain and metal. However, they allowed the previously suggested possibility of a discrete oxide layer at the interface and stated that, if it is present, it must be adherent to the metal. They offered a variation of the "interface saturation theory" which was that a mono-molecular layer of oxide stays present between the oxide- 
saturated glassy phase and the metal. ${ }^{52}$ Thus, introductory theories have changed from the oxide layer on the alloy completely dissolving into the porcelain (bonding between "oxide-saturated glass" and metal) to the oxide layer on the metal lending ions to the ceramic while maintaining itself as a discrete layer which is strongly adherent to the alloy.

Several authors have furthered this initial, industrial research with various experimental findings specific to dental materials. In 1962 Shell and Nielsen's landmark paper excited the dental world. The authors designed an experiment to test the strength of the porcelain-alloy bond and then used collected numerical data to describe the nature of the bond. It was their conclusion that the most important factor determining the strength of the bond is the inter-atomic bonding, specifically "a mixture of ionic, covalent, and metallic". Additionally, the importance of reducing the amount of residual stress gradients created by the differing thermal contraction coefficients to allow "freedom from shear stresses" was addressed. ${ }^{8}$

Furthering the oxide layer research and analysis, Szantho von Radnoth and Lautenschlager ${ }^{43}$ proposed that a particular oxide, solely responsible for bonding, was formed during the firing of the porcelain with the alloy. This suggested that the oxide layer, which is formed during the degassing process of the alloy, might not be the oxide layer that is entirely responsible for the bond.

Vickery and Badinelli, ${ }^{50}$ determined to identify the individual component forces contributing to a porcelain-gold bond, found that the effect of compressive bonding forces--exerted by the differences in thermal expansion of the two phases--was much more significant than the van der Waal's bonding forces.

Mackert et al determined in 1984 that "the fusing porcelain comes in contact with the oxide rather than the metal surface". ${ }^{50}$ This experimental group further determined that if the oxide is not adherent to the metal substrate, the resultant porcelain-metal bond 
will be weak. They postulated two requirements for the porcelain to metal bond: first an oxide layer must be present at the interface and second, the oxide layer must be adherent to the metal. ${ }^{49}$

Oxide layers can be analyzed and designed with knowledge of the PillingBedworth ratio $(R)$ that correlates the porosity of a metal oxide with the specific density of the alloy. It is defined as the ratio of the volume of the metal oxide to the consumed metal volume.

$$
\mathrm{R}=\frac{\mathrm{V} \text { metal oxide produced }}{\mathrm{V} \text { metal consumed }}
$$

Pilling and Bedworth discovered that when $\mathrm{R}$ was less than 1 the oxide layer tended to be porous and did not cover the entire metal surface. ${ }^{53}$

The quality and quantity of the oxide layer on the dental alloy surface can influence the bonding strength between the metal and the porcelain. Today, it is commonly known that an oxide layer which is too thick results in a poor metal-ceramic bond. ${ }^{8,9,43,49,54-56}$ The thickness of an oxide layer is dependent on the degree of oxidation (both amount and diffusion rate) of metal elements within the alloys. ${ }^{40}$

The precise conformation of the chemical bond of porcelain to metal has yet to be determined, other than targeting oxides shared between the porcelain and metal as culprits responsible for the bond. It is known that differing oxide properties and layers influence the bond. However the modeling of each element, present in both porcelain and alloy, and its specific contribution to the interface has not been determined.

\section{Interfacial Morphology}

Interestingly, Shell and Nielsen ${ }^{8}$ concluded that a mechanical bond did not "play an important role in the bond strength proper", stating that "roughening per se did not add to the shear resistance at the bond." There have been several, conflicting theories 
regarding the effects of interfacial morphology and its contribution to the bond strength of ceramic and metal. ${ }^{3,14,42,56-58}$ Roughness, on the surface of the metal, has been speculated to weaken the porcelain-metal interface by causing stress concentrators which initiate (brittle) ceramic fracture. ${ }^{12,57}$ In addition, irregularity might cause incomplete contact between the metal and the ceramic, and trap gasses, reducing bond strength. $^{8,13,56}$ Alternatively, it is postulated surface morphology can amplify bond strength with added mechanical attachment or increased area for chemical bonding. ${ }^{23,42,58,59}$

Wagner in a definitive, thorough experiment in 1993 tested a range of interfacial treatments in two aspects: modification of both chemistry and morphology of the interface. He concluded succinctly that none of the "maladies reported in the literature, either stress raisers caused by rough interface or trapped gases in the valleys, caused lowered bond strengths", adding that, "it appears that roughness is entirely beneficial to porcelain-metal bonding. ${ }^{42}$ 


\section{MATERIAL AND METHODS}

ISO 9693:1999(E) Metal Ceramic Dental Restorative Systems ${ }^{60}$ specifies requirements and testing methods for dental metallic materials and ceramic materials used in combination as a composite structure. The material requirements and testing methods were followed for this investigation. (Figure 2)

\section{Castings}

Two metal alloys were used: a base-metal alloy, Duceranium U (DU) (Dentsply International, York, PA) and a high noble alloy Encore (E) (Dentsply International, York, PA). The composition of each alloy is found in weight percent in Table I. Wax patterns made from 22-guage casting wax (Green Casting wax; Corning Rubber Co., Brooklyn, NY) were cut into nominally flat strips $25 \mathrm{~mm} \times 3 \mathrm{~mm} \times 0.5 \mathrm{~mm}(1 \times w \times h$.) The patterns were sprued and invested in a carbon-free phosphate-bonded investment (Fujivest II; GC America, Alsip, IL). Seventy-five castings of each alloy were made using a natural gas and oxygen blowpipe (Harris 50-10; Harris Calorific Inc., Gainesville, GA), with a centrifugal casting machine (Centrifico Casting Machine; KerrLab Corp., Orange, CA). Castings were allowed to cool at room temperature, were divested and cleaned by

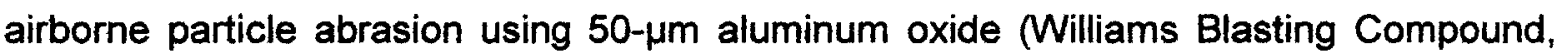
Ivoclar Vivadent Inc., Amherst, NY) with 4-bar air pressure. The sprue and sprue-buttons were cut off the alloy strips for proper finishing and refining to desired, final dimensions. All specimens were subjected to ultrasonic cleaning with distilled water for 10 minutes.

\section{Surface preparation}

Manufacturer recommendations were followed for finishing and surface preparation procedures. Alloy specimens were adjusted to ISO 9693 standard dimensions $(25 \mathrm{~mm}$ length $\times 3 \mathrm{~mm}$ width $\times 0.5 \mathrm{~mm}$ height) with aluminum oxide barrel 
burs (Shofu Corporation, San Marcos, CA) and a laboratory handpiece (SynchroTorque; Handler Mfg., Westfield, NJ). Separate burs were used with each alloy, while wearing nitrile gloves and changing gloves for each alloy group. Dimensions were verified using a Boley gauge (Hu-Friedy, Chicago, $\mathrm{IL}$ ). Specimens were engraved with a number using a quarter-round cutting instrument (SS White Burrs Inc., Lakewood, NJ) in a high-speed laboratory handpiece (K-AIRplus; KaVo Dental Corp., Lake Zurich, IL), on the side opposite to where porcelain would be applied, for future identification purposes. On the side receiving porcelain, bars were lightly marked with two lines perpendicular to the long axis of the bar and $8.5 \mathrm{~mm}$ from each end using a sharp blade (No. 11; BD Surgical Products, Franklin Lakes, NJ). These lines delineated the extent of the porcelain application that would be made. (Figure 3)

Three ceramic furnaces were used (Ceramco Phoenix Quick Cool; Dentsply International York, PA) and were calibrated according to manufacturer's recommendations. (Figure 4) All specimens were suspended on a firing platform to simulate the standard level of a crown framework within the oven muffle during the oxidization procedure. (Figure 5) The oxidation cycle for the Duceranium $U$ alloy required heating specimens with a rate of $55^{\circ} \mathrm{C} / \mathrm{min}$ from $650^{\circ} \mathrm{C}$ to $1010^{\circ} \mathrm{C}$ under vacuum and holding the temperature for 5 minutes. The oxidation cycle for the Encore alloy required heating specimens with a rate of $55^{\circ} \mathrm{C} / \mathrm{min}$ from $650^{\circ} \mathrm{C}$ to $1038^{\circ} \mathrm{C}$ with no vacuum for 5 minutes. (Table II)

The Duceranium U specimens were steam-cleaned (Triton SLA Wet and Dry Steam Cleaner; Bego, Bremen, Germany) with distilled water, oxidized, and then airabraded $(50 \mu$ aluminum oxide with 4 bar air pressure). Thus, the oxide layer was partially removed by passing the nozzle over the surface twice at a distance of $5 \mathrm{~cm}$ for less than one second until the specimens had a uniform appearance. 
Encore specimens were steam-cleaned with distilled water, air abraded (following air abrasion procedure described previously) on the side for porcelainapplication only (to avoid re-etching specimen numbers and potential contamination) and then oxidized. Fifty-six specimens with sufficient dimensions from each alloy group were protectively wrapped and underwent surface analysis at a later date.

\section{Surface analysis}

The American National Standards Institute describes surface texture as "the repetitive or random deviation from the normal surface that forms the three dimensional topography of a surface". Average roughness $(\mathrm{Ra})$ is used to detect general variations in overall profile height and $\mathrm{Rq}$ (root mean-square average) measures roughness profile from the mean line. Ra measures peaks and valleys and $\mathrm{Rq}$ detects differences in spacing and distribution of the peaks and valleys. ${ }^{64}$ Specimen surfaces to which porcelain would be added were analyzed using a surface profilometer (DekTak 8; Veeco Instruments Inc. Woodbury, New York) to determine roughness of Duceranium $U$ and Encore specimens to be used. The DekTak8 profiler includes both $\mathrm{Ra}$ and $\mathrm{Rq}$ functions. (Figure 6)

\section{Opaque porcelain application}

The profiled specimens were re-measured in multiple spots with a Boley gauge to select specimens which best corresponded with ISO 9693 specifications. Twentyeight specimens of each alloy group were determined acceptable for porcelain application.

One-half of the Duceranium $U(n=14)$ and one-half of the Encore specimens $(n=14)$ received an opaque layer, whereas the other half did' not. The remaining specimens were kept dry and under vacuum until dentin porcelain application. Ceramco 3 powder opaque (Dentsply Ceramco, Burlington, NJ) and Vita 900 paste opaque 
(Vident, Brea, CA) were used with half $(n=7)$ of both Duceranium $U$ and Encore specimens. (Figure 7) The CTE of both porcelains were given as a range from the manufacturer. Ceramco 3 is "to be used with alloys with a CTE of 13.9 to $14.9 \times 10^{-6} /{ }^{\circ} \mathrm{C}$ ", and Vita 14.0 to $14.4 \times 10^{-6} /{ }^{\circ} \mathrm{C}$. (Personal communication with Laboratory Technicians at Dentsply Ceramco and Vident.) The CTE of both Duceranium $U$ and Encore alloys is $14.1 \times 10^{-6} /{ }^{\circ} \mathrm{C}$.

Vita 900 paste opaque was added with a clean glass rod. The Ceramco 3 opaque powder was mixed with distilled water to make a paste. This paste was added to the strip with a small, clean flat brush. Thin even coats were applied to specimens, which were then dried in front of the porcelain oven for approximately 10 minutes. All specimens were suspended on a firing platform to simulate the standard level of a crown framework within the oven muffle during the opaque firings. (Figure 8) The Vita 900 specimens were fired at $500^{\circ} \mathrm{C}$ and held for 6 minutes. Following this, during another six minutes, the temperature increased to $900^{\circ} \mathrm{C}$ and was held for 3 minutes followed by 6 minutes under vacuum. The Ceramco 3 opaque specimens were fired at $500^{\circ} \mathrm{C}$ under continuous vacuum to $975^{\circ} \mathrm{C}$ for 5 minutes. All specimens were not completely masked with this first layer of opaque, therefore an additional layer of opaque was added to each specimen. Second layers were added after specimens cooled. The Ceramco 3-second opaque firing schedule was unchanged from the first layer firing. The second Vita 900 opaque firing was the same as the first firing, however it was held at the high temperature for 2 minutes prior to the 6-minute vacuum. (Table III) After two opaque layers, the metal alloy strips were successfully masked with opaque porcelain. This opaque application was aimed to mimic the average thickness of opaque porcelain when added at the dental laboratory for crown frameworks. 


\section{Dentin (Body) porcelain application}

The dentin porcelains selected were Ceramco 3 (Dentsply) and Vita 900 (Vident). Dentin porcelain was added to all 56 specimens (28 Duceranium $U$ and 28 Encore) whether or not opaque porcelain was added previously. Again one half of each alloy $(n=14)$ had Ceramco 3 dentin porcelain added and one half of each alloy $(n=14)$ had Vita 900 added. The number of Duceranium $U$ and Encore bars without opaque was 7 for each porcelain group. All body porcelain additions were made according to manufacturers' specifications. All specimens were suspended on a firing platform to simulate the standard level of a crown framework within the oven muffle during the dentin firings. Ceramco 3 specimens were fired at $650^{\circ} \mathrm{C}$ to $960^{\circ} \mathrm{C}$ for both firings. Vita 900 specimens were fired at $600^{\circ} \mathrm{C}$ to $900^{\circ} \mathrm{C}$ for the first firing and $600^{\circ} \mathrm{C}$ to $890^{\circ}$ for the second firing. (Table III) Porcelain was added to each of the specimens by hand, in excess anticipating shrinkage, and ground to ISO Standard 9693:1999 (E) after two firings. (Figure 9) Measurements were made with a Boley gauge (Hu-Friedy) in multiple (6-8) locations on the porcelain strip to ensure the porcelain layer was flat and symmetrical.

Specimen porcelain areas were grossly trimmed with clean, porcelain-use-only diamond burs (836.11.014; Brasseler USA, Savannah, GA) and a high-speed laboratory handpiece (K-AIRplus; KaVo Dental Corp., Lake Zurich, IL). That is, all specimens were measured to have a consistent $1 \mathrm{~mm}$ thick porcelain application symmetrically placed in the center of the $25 \mathrm{~mm}$ strip after finishing. Porcelain was polished with porcelain polishing burs (Dialite; Brasseler USA). Specimens were kept in a dry environment under vacuum until testing to avoid moisture contamination. 


\section{Bond Strength Determination}

Codes used for describing the structure of metal-ceramic flexure bars were Duceranium U (D), Encore (E), Ceramco $3(C)$, Vita $900(V)$, Opaque $(O)$, non-Opaque (N). Metal-ceramic specimens evaluated were EOC (Encore -Opaque-Ceramco 3), DOC (Duceranium U-Opaque-Ceramco 3), ENC (Encore-non-Opaque-Ceramco 3), DNC (Duceranium U-non-Opaque-Ceramco 3), EOV (Encore-Opaque-Vita 900), DOV (Duceranium U-Opaque-Vita 900), ENV (Encore-non-Opaque-Vita 900), DNV (Duceranium U-non-Opaque-Vita 900). (Figure 10)

Metal-ceramic bond characterization was determined using the Schwickerath crack initiation test a method described in ISO 9693 : 1999 (E). ${ }^{60}$ The debonding strength/crack initiation strength for materials loaded in a 3-point flexure test configuration is determined by the equation:

$$
\tau_{b}=k \cdot F_{\text {fail }}
$$

where $\tau_{b}$ is the debonding strength/crack initiation strength in MPa. The coefficient $k$ is a function of both the thickness of the metal and the elastic modulus of the alloy. It is determined from a table contained in ISO 9693:1999 (E) ${ }^{60}$ (Graph 1) The Young's (elastic) modulus for the Encore alloy is $178 \mathrm{GPa}$ and for Duceranium $\mathrm{U}$ is $153 \mathrm{GPa}$. $F_{\text {fail }}$ is the measurement of load (in Newtons) applied to the specimen at that point in time when the ceramic debonded from the metal alloy (load at failure). The ISO 9693:1999 (E) standard for acceptable porcelain-alloy bond strength is $25 \mathrm{MPa}$.

Eight groups containing at least 6 flexure bars were tested in a mechanical testing device (Model 5581; Instron Corporation, Canton, MA). The three-point bending apparatus had a support span of $20.0 \mathrm{~mm}$. A center load was applied at a crosshead speed of $1.50 \mathrm{~mm} / \mathrm{min}^{-1}$. A $50-\mathrm{N}$ load cell was used for all testing (Instron Corp.) All 
specimens were placed in the mechanical testing device so that the porcelain layer was opposite the applied load, and testing was halted following a 5\% drop in load. (Figure 11) Load-versus-displacement curves were generated for each specimen. (Figure 12)

Pilot studies suggested that it would be difficult to determine, from load-versuscrosshead extension curves, the precise point at which initial metal-ceramic failure occurred. Many studies ${ }^{9,17,61-63}$ in the literature record "load at catastrophic failure" to determine bond strength. However, there are two problems associated with that method: first, the load-versus-extension curves do not maintain linearity, and second, metal-ceramic bond failure generally occurs prior to catastrophic failure.

To help determine a defined initial metal-porcelain failure, a precision measurement microphone (Model M53, LinearX Systems Inc., Tualatin, OR) was placed in close approximation to the test specimen (Figure 13) and amplitude versus time graphs were generated using noise analysis software (pcRTA, Version 2.30; LinearX Systems Inc.). (Figure 14) The pilot study suggested that initial metal-porcelain failure was best simultaneously observed and recorded at $5-$ and $10-\mathrm{kHz}$. In the noise analysis control panel the pink noise generator was selected and an American National Standards Institute-A (ANSI-A) weighted filter was used with the dynamic range fixed between -60 and $+20 \mathrm{dBm}$. Pink noise is the most common noise source used during noise analysis. It also produces a flat line during noise analysis, since pink noise is energy versus log frequency, and the noise analysis software displays log frequency. The selection of the ANSI-A weighted filter helped attenuate low frequencies while allowing higher frequencies to pass relatively unattenuated. Noise analysis was started at the same time as the flexure test so that there would be a time correspondence between the amplitude versus time curves and the load-versus-displacement curves. 
(Figure 15) Load at initial failure was determined from the load-versus-crosshead extension curves and confirmed with the noise analysis curves.

\section{Debonding analysis}

Two failure modes can be encountered using a 3-point flexure test using flexure bars with geometry described by Fig. 2. Cracks forming between the ends of the ceramic layer and on the tensile surface indicate that the porcelain's flexural strength has been exceeded. However, cracks forming on one end of the porcelain layer indicate that the combined shear and normal stresses at the metal-ceramic junction were responsible for debonding ${ }^{67}$ In this study, the latter mode constituted a valid test. Therefore, following testing each specimen was observed using light microscopy (Wild M8, Heerbrugg, Switzerland) at $\times 20$ to $\times 80$ magnification to determine whether or not a satisfactory test was completed. Basic fuchsin dye penetrant (Medical Chemical Corp., Torrance, CA) was applied to the debonded bar to assist with visualization of the failure origin. In addition, three flexure bars from each group were polished to 600 grit on one side using a metallographic polisher (Metaserv 2000; Buehler Ltd., Lake Bluff, IL) and then evaluated by scanning electron microscopy (SEM) (LEO 1450VP SEM System; Carl Zeiss Micro Imaging Inc.; Thornwood, NY) to determine the mode of failure. None of the specimens failed with cracks occurring in the middle of the ceramic layer, which would have indicated an inappropriate failure mode according to Schwickerath test standards. (Figure 16)

\section{Data analysis}

Data included three variables: porcelain, opaque, and metal. A covariate was the surface roughness of the metal bars. Overall results can be found in Table IV. Data were statistically analyzed using a 3-way analysis of variance (ANOVA), and the Tukey HSD test was used for all pairwise multiple comparisons $(\alpha=.05)$ using statistical software 
(Sigma Stat for Windows Version 2; Jandel Corp., San Rafael, CA). (Table V) In addition, Spearman's correlation was used to determine the relationship between $\mathrm{Ra}$ values and bond strength. (Table VI) 


\section{RESULTS}

The use of a precision measurement microphone resulted in the selection of load values that were lower than the peak (catastrophic) load recorded on the load-versusdisplacement curves during testing. The 3-way ANOVA indicated a statistically significant difference $(P=.028)$ between the debonding strength/crack initiation strength of opaqued and non-opaqued specimens metal-ceramic bars. In addition, the interaction between opaque and metal was statistically significant $(P=.048)$ No other interaction or their effects were significant. (Table V)

The mean values of the debonding strength/crack initiation strengths of the metal-ceramic systems are listed in Table VII. The differences in debonding strength/crack initiation strength were not statistically significant. The alloy-opaqueporcelain system with the greatest bond strength was EOC; alternatively, the system with the lowest bond strength was DNV. All bars receiving opaque prior to body porcelain application achieved a bond strength greater than $25 \mathrm{MPa}$ and therefore met requirements set forth by ISO 9693:1999 (E) for metal-ceramic systems. For flexure bars without opaque, DNC and ENV achieved a debonding strength/crack initiation strength exceeding $25 \mathrm{MPa}$ thus meeting ISO 9693:1999(E) requirements, however groups DNV and ENC did not achieve 25MPa. That is, 6 of the 8 metal-ceramic groups tested had debonding strengths/crack initiation strengths which would pass the ISO 9693:1999 (E) standard for bond strength of acceptable metal-ceramic pairs. (Graph 2)

Addition of opaque to the Encore alloy (EO) resulted in a significantly higher debonding strength/crack initiation strength than Encore without opaque (EN) $P=.0019$ ). There was no significant difference between debonding strength/crack initiation strength for Duceranium U with opaque (DO) and without opaque (DN). (Table VIII)

None of the flexure bars failed from cracks initiating on the tensile surface, rather each failed at the metal-ceramic junction at one end of the porcelain veneer addition. 
Flexure bars with Vita 900 porcelain with and without opaque and Ceramco 3 porcelain with opaque exhibited adhesive failure modes. Adhesive failures occurred between the metal oxide and opaque or between the metal oxide and the body porcelain when no opaque was used, but not between the body porcelain and opaque porcelain. (Figure 17) It is interesting to note two groups contained cohesive failures, the Duceranium $U$ with Ceramco 3 porcelain system without opaque (DNC) and the Encore with Ceramco 3 porcelain system without opaque (ENC). (Figure 18) The Ceramco 3 range of CTE was significantly larger than that of Vita porcelains. However there was no significant difference in bonding strengths one porcelain system to the other.

Only 5 individual specimens ( 3 Duceranium $U$ and 2 Encore metal-ceramic flexure bars) exhibited linear-elastic behavior on the load-versus-displacement curves regardless of the system evaluated; all other metal-ceramic specimens demonstrated non-elastic behavior during flexure testing. Furthermore, the noise analysis peaks at the 5- and $10-\mathrm{kHz}$ coincided with the point on the load-versus-displacement curves where there was no longer a straight-line relationship. (Figure 15)

There was no correlation found between alloy $\mathrm{Ra}$ values and bond strength. (Graph 3) 


\section{DISCUSSION}

It is known that metal-ceramic bonding depends on chemical interaction between the porcelain and the metal alloy. The alloys and porcelains chosen for this study were aimed to represent popular choices made for metal-ceramic crown restorations in the United States.

In this study it was found that there is a statistically significant difference in debonding strength/crack initiation values with the addition of opaque porcelain. The null hypothesis, which stated that there is no difference, must therefore be rejected and the alternative selected.

While it is understood that debonding occurs when the relationship between load and crosshead displacement is no longer a straight line, the ISO 9693:1999 (E) is unclear regarding what specific load point corresponds to initial debonding of a metalceramic system. The specification states stop the test at a $5 \%$ load drop, and this was where the metal bar exhibited elastic elongation. The porcelain can not stay adherent along the entire surface of the bar at this time. There is a certain ambiguity as to the exact stopping point of this test, and as such, the specific determination of debonding strength/crack initiation becomes complicated.

Initial debonding can and should not be determined as the equivalent of the maximum-recorded load. This maximum load is most likely correlated to debonding and eventual delamination of the porcelain veneer. For this test it was determined initial debonding/crack initiation was defined by the coincidence of three analyses:

1. The point on the load-versus-displacement curves where plastic deformation occurred (stray from a straight line)

2. Peaks in the $5-$ and $10-\mathrm{kHz}$ frequencies recorded

3. Analysis of porcelain delamination with SEM 
For this study, the point of initial metal-ceramic debonding was lower than the peak load point on load-versus-displacement curves. It should be noted that if the peakload value were used all of the specimens tested would pass the minimum bonding strength requirement $(25 \mathrm{MPa})$ set in ISO 9693:1999 (E). The question thus may arise, that previous studies using this ISO standard, to determine metal-ceramic bonding strengths, could have been overestimated if those systems tested behaved similarly to those in this study and the peak-load value was used as $F_{\text {fail. }}$ Regardless, this study found that two metal-ceramic systems tested were not within the ISO standard of $25 \mathrm{MPa}$, and both did not have an opaque layer.

The test was stopped at a $5 \%$ load drop, with minimum damage accumulated, and SEM images demonstrating debonding had occurred at one end (with a crack propagating toward the intact end). The mode of failure for the specimens was stated to be both adhesive and cohesive through SEM analysis. However the true failure mode would be best determined after the removal of the cracked porcelain veneer and analysis performed with an energy dispersive spectrometer, because it may be difficult to distinguish between body and opaque porcelain remnants on the metal bar. In this study it was determined that testing should be halted prior to complete debonding of porcelain so that a failure sequence could be evaluated.

Clinically, "ideal" metal-ceramic failure would be cohesive in nature (within porcelain). That is, the bond between metal and porcelain should be greater than the cohesive strength of the porcelain. If this were the case, we would not have questions regarding the integrity of the metal-ceramic bond and/or the materials employed. For this study, the predominant failure mode was adhesive ( 6 out of 8 groups). It is interesting to note that the two more "ideal" failure modes (cohesive) were within specimens with no opaque used. A similar result was found for Lehner and Holtan ${ }^{22}$ using specimens without opaque. 
Many bonding strength tests exist in dental materials science, each focusing on a different fracture mechanism of the porcelain. ${ }^{65-66}$ The decision to use the Schwickerath test (the ISO standard) was made for several reasons. Besides being the industry standard, the three-point flexure test has several advantages. Fabrication of specimens has been said to be "easy" ${ }^{167}$ and was determined to be relatively straight-forward, however as Quinn states, "the test appears deceptively easy but requires some care in specimen preparation and test execution to obtain results with low error and consistency between laboratories ${ }^{n}{ }^{68}$ Specimen dimensions can mimic clinical situations fairly closely in regards to metal and porcelain thickness and flexure of a Fixed Partial Denture connector. The stress values generated are mean values over a certain range and for most material combinations, the 3-point flexure test yields the same relative rating in bond strengths as measured in other experiments. ${ }^{67}$

Critics of the test state that because maximal tensile stresses are created at the surface of the porcelain, predictable tensile failures result. ${ }^{65,66}$ However our initial pilot study included FEM analysis and disputes this statement; the peak stresses in the composite strip occur at the end of the porcelain. (Figure 19)

A second criticism comes from the questionable analysis of stress states present at the interface ${ }^{69}$ However, Lenz et al, agreeing that the stress states at the porcelain metal junction-edge were complex, analyzed the junction stresses with FEM and mathematical formulae. These authors used a method that allowed the calculation of mean stress values, along the porcelain-metal junction of the strip, independent of the precise distribution of stresses at the edge of the specimen.

The question can be asked, does the ceramic breakage depend too much on the elastic modulus (Em) of the metal tested? ${ }^{66}$ According to Lenz et al when the initial testing was done proposing the Schwickerath test as the ISO standard for metal-ceramic bond strength, several alloys were used with varying Ems (80GPa to $240 \mathrm{GPa}$ ) and 
there was no significant difference between bonding strengths as based on Em. "The ratio of mean shear stress to mean tensile stress [thus] amounts to $\approx 1$ for all possible material combinations...for all material combinations the zone of tensile normal stress has the same extension, [it is] clear that in these experiments the bond strength is always tested under similar stress conditions. ${ }^{67}$ Furthermore, the Em of the alloy is taken into consideration in the coefficient $k$ value in the equation to determine bond strength.

Anusavice et al completed a comparative analysis of eleven metal-ceramic-metal bond tests using FEM in $1980 .^{65}$ The authors analyzed only the shear stress states distribution along each theoretical metal-porcelain interface. They found that 3 tests (the 3- and 4-point flexure tests and the rectangular parallel shear test) were least likely to exhibit failure in porcelain only. However the two bending tests indicated high stress concentration values which may cause bond failures at lower average stresses than would be required to cause bond failures in other systems. It was also acknowledged that the FEM calculations were based on a perfect bond between metal and porcelain, and stress disturbance effects were assumed to be negligible. It was concluded that due to stress concentrations, "average bond strength values calculated from laboratory tests [are] expected to be generally lower in magnitude than the stresses which would result in the absence of stress risers."

While bond strengths of the majority of groups tested here were above the ISO standard of $25 \mathrm{MPa}$, it is obvious that the base metal specimens have the most significant results regarding the absence of opaque. Debonding failures occurred in anticipated areas. It can be assumed the porcelain surface finish must have been consistent, with no flaws present to initiate an unwanted fracture in the middle of the specimen. Also, attempts were made to maintain integrity of specimens by keeping specimens under dry vacuum until testing, to avoid moisture contamination and the 
potential problems with ceramic crack propagation. ${ }^{70-71}$ During fabrication of specimens however, four base-metal specimens failed prematurely. There were three specimens lacking opaque in which the ceramic completely broke free of the metal strip during finishing of the porcelain. These specimens were numbers $20,49,5$ and the alloy strips were steam cleaned with distilled water and porcelain re-added.

The mode of failure for Duceranium $U$ specimens was both cohesive and adhesive. For all specimens tested, the ceramic was not allowed to wholly fracture off of the alloy strip. Recording of the initial crack (failure) was important to register the precise failure time/load values. It was for this reason that two separate recording methods were used to determine the exact time of failure. It is important to not allow the test to continue (increased load on specimen) to avoid incorrect load values and subsequent erroneous bond strength values. The load-to-failure results are considerably lower with this acoustic assistance, than those results expected with the load-versus-displacement curves alone. (Figure 15)

Duceranium $U$ demonstrated a modest difference between debonding strength/crack initiation strength with and without opaque, as compared to Encore with and without opaque. It could be reasoned that the Duceranium $U$ specimens had adequate bonding between body porcelain and the alloy because of additional oxide elements present in the alloy. "A major difference in the bonding behavior between precious and non-precious alloys stems from the difference in availability of readily oxidizable base metal elements. ${ }^{n 2}$ In 1977 Anusavice et al studied the bonding mechanism between ceramic and non-precious alloys with $x$-ray energy analysis. ${ }^{24}$ Elemental couples were analyzed. Authors found a Cr-O-Al complex was formed between the alloy and the ceramic and credited $\mathrm{Cr}$ (from the alloy) for connecting with the ceramic layer. Murakami and Schulman ${ }^{12}$ state the positive characteristics of nonprecious alloys include: A low specific gravity that is one-half that of gold alloys, an Em 
over two times that of gold alloys, a high-yield strength, and a sag resistance that is nine times greater (than gold) because of high melting temperature. These characteristics may also have contributed to the Duceranium $U$ metal-ceramic specimens having high bond strength values. The Encore alloy used may not have had a mature, useful oxide layer to achieve bond strengths comparable to the use of opaque. Application of body porcelain directly to Duceranium $U$ and Encore metal alloys can, in some circumstances, produce an acceptable bond according to ISO 9693:1999 (E). (Table VIII)

The significance of interfacial morphology as a variable could not determined in this study. Further testing is needed with more adequate variation of specimen $\mathrm{Ra}$ and $\mathrm{Rq}$ to determine if there may be a statistically significant effect. 


\section{CONCLUSIONS}

The following conclusions were made:

1. Presence of opaque porcelain generally increased the debonding strength/crack initiation strength for metal-ceramic systems, however magnitude varies with the particular alloy and porcelain combination.

2. Opaque porcelain may not be necessary for a clinically adequate metal-ceramic bond for some metal-ceramic systems.

3. Initial failure during debonding strength/crack initiation strength testing corresponds to the point on the load-versus-displacement curves where there is no longer a straight line.

4. Acoustic measurements in coordination with load-versus-displacement curves allow more precise determination of initial failure during three-point metal-ceramic flexure testing. 


\section{FUTURE RESEARCH}

The findings of this study provide the following future research opportunities:

1. Further evaluation of the exact materials limited to this study with other, established metal-ceramic bond tests (such as the pull-shear test, oxide adherence test, thermal expansion testing, and thermal shock testing.)

2. To determine future metal-ceramic working pairs which do not require opaque porcelain for satisfactory bond strengths.

3. Specific oxide analysis to characterize exact elemental, working pairs responsible for bond in order to:

a. further define exact chemical nature of metal-ceramic bond.

b. to coat to high noble alloys for future metal-ceramic bond tests.

4. Wear testing to determine wear rates of enamel opposing both polished or glazed opaque porcelain.

5. Wear testing to determine difference in wear rates of exposed opaque porcelain alone versus an exposed margin of metal and opaque porcelain. 


\section{BIBLIOGRAPHY}

1. O'Brien WJ Strengthening mechanisms of current dental porcelains. Compend Contin Educ Dent 2000;21:625-30.

2. Cornell DF, Kois JC, Rifkin LR. Advances in ceramic restorations. Compend Contin Educ Dent 2002;25:450-62.

3. McLean J. Evolution of dental ceramics in the twentieth century. J Prosthet Dent 2001;85:61-66.

4. Preston JD. Rational approach to tooth preparation for ceramo-metal restorations. Dent Clin North Am 1977;21: 683-698.

5. Brecker SC. Porcelain baked to gold-a new medium in prosthodontics. J Prosthet Dent 1956;6:801-10.

6. Johnston JF, Dykema RW, Cunningham DM. The use and construction of gold crowns with a fused porcelain veneer-a progress report. J Prosthet Dent 1956;6:811-21.

7. Naylor WP. Metal Ceramic Technology. Quintessence Publ Co. Chicago, IL 1992.

8. Shell JS, Nielsen JP. Study of the bond between gold alloys and porcelain. J Dent Res 1962;41:1424-143.

9. Mackert JR, Parry EE, Hashinger DT, Fairhurst CW. Measurement of oxide adherence to PFM alloys. J Dent Res 1984;63: 1335-40.

10. Lacy AM Ceramometal restorations. In: Eissmann et al, eds. Dental Laboratory Procedures. Fixed Partial Dentures. Volume II Chapter 13CV Mosby Co. St. Louis, IL: 1980.

11. McLean JW, Sced IR. Bonding of dental porcelain to metal II. The base-metal alloy/porcelain bond. Trans Br Ceram Soc 1973;5:235-8.

12. Murakami I, Schulman A. Aspects of metal-ceramic bonding. Dent Clin North Am 1987;31:333-46.

13. Craig RG, Ward ML Restorative Dental Materials 10 th ed. Chapter 18 Mosby-Year Book St. Louis, MO 1997.

14. Wight TA, Bauman JC, Pellen GB. An evaluation of four variables affecting the bond strength of porcelain to non-precious alloys. J Pros Dent 1977;37: 570-7.

15. Knap F, Ryge, G. Study of bond strength of dental porcelain fused to metal. J Dent Res 1966;45:1047-51.

16. Lund PS, Goodkind RJ, Swanson S. Residual stress in several ceramometal systems. J Prosthet Dent 1989;62: 278-83. 
17. Coffey JP, Anusavice KJ, Dehoff PH, Lee RB, Hojjatie B. Influence of contraction mismatch and cooling rate on flexural failure of PFM systems. J Dent Res 1988;67:61-5.

18. Fairhurst CW Anusavice KJ, Ringle RD, Twiggs SW. Porcelain-metal thermal compatibility. J Dent Res. 1981;60:815-9.

19. Asaoka K, Tesk JA. Transient and residual stress in a porcelain-metal strip. J Dent Res 1990;69: 463-469.

20. Claus $H$. The structure and microstructure of dental porcelain in relation to firing conditions. Int J Prosthodont 1989;2:376-84.

21. Rosensteil SF, Land MF, Fujimoto J. Contemporary Fixed Prosthodontics $3^{\text {rd }}$ ed. $p$. 617, C.V. Mosby Co. St. Louis, IL 2001.

22. Lehner $\mathrm{C}$, Holtan J. A comparison of the bond strength of opaque and body porcelains on different types of ceramo-metal alloys. Schweiz Monatsschr Zahnmed 1988;98: 937-943.

23. al Mutawa NJ, Sato T, Shiozawa I, Hasegawa S, Miura H. A study of the bond strength and color of ultralow-fusing porcelain. Int J Prosthodont. 2000 MarApr;13(2):159-65.

24. Anusavice KJ, Ringle RD, Fairhurst CW. Bonding mechanism evidence in a ceramicnon precious alloy system. J Biomed Mater Res 1977;11: 701-709.

25. Monasky GE, Taylor DF. Studies on the wear of porcelain, enamel, and gold. J Prosthet Dent 1971;25:299-306.

26. Verrett, RG. Analyzing the etiology of an extremely worn dentition. J Prosthet Dent 2001;10:224-233.

27. DeLong R, Sasik C, Pintado MR, Douglas WH. The wear of enamel when opposed by ceramic systems. Dent Mater 1989;5:266-71.

28. Mair LH. Understanding wear in dentistry. Compend Contin Educ Dent 1999; 20:1932.

29. Hattab FN, Othman MY. Etiology and diagnosis of tooth wear: a literature review and presentation of selected cases. Int J Prosthodont 2000;13:101-107.

30. Turner KA, Missirlian DM. Restoration of the extremely worn dentition. J Prosthet Dent 1984;52: 467-74.

31. Mahalick JA, Knap FJ, Weiter EJ. Occlusal Wear in Prosthodontics. J Am Dent Assoc 1971;82:154-158.

32. Oh WS, Delong R, Anusavice KJ. Factors affecting enamel and ceramic wear; a literature review. J Prosthet Dent 2002;87:451-9. 
33. Magne P, Oh WS, Pintado MR, DeLong R. Wear of enamel and veneering ceramics after laboratory and chairside finishing procedures. J Prosthet Dent. 1999;82:669-79.

34. Kelly JR, Nishimura I, Campbell SD. Ceramics in dentistry: historical roots and current perspectives. J Prosthet Dent 1996;75:18-32.

35. Ward et al. Surface roughness of opalescent porcelain after polishing. Oper Dent. 1995 20:106-10

36. Ramp MH, Ramp LC, Suzuki S. Vertical height loss: an investigation of four restorative materials opposing enamel. J Prosthodont 1999;8:252-7.

37. Sulong MZ, Aziz RA.Wear of materials used in dentistry: a literature review. J Prosthet Dent 1990;63:342-9.

38. Seghi RR, Rosenstiel SF, Bauer P. Abrasion of human enamel by different dental ceramics in vitro. J Dent Res 1991;70:221-5.

39. Clelland NL, Agarwala V, Knobloch LA, Seghi RR. Relative wear of enamel oppposing low-fusing dental porcelain. J Prosthodont 2003;12:168-75.

40. Ebbing, DD. General Chemistry, $4^{\text {th }}$ edition. Chapters, 2, 9, 21: Boston, MA, Houghton Mifflin, 1993.

41. Fairhurst CW, Anusavice KJ, Hashinger DT, Ringle RD, Twigg SW. Thermal expansion of dental alloys and porcelain. J Biomed Mater Res 1980;14: 435-446.

42. Wagner WC, Asgar K, Bigelow WC, Flinn RA. Effect of interfacial variables on metalporcelain bonding. J Biomed Mater Res. 1993;27:531-7.

43. Szantho von Radnoth M, Lautenschlager EP. Metal surface changes during porcelain firing. J Dent Res 1969;48: 321-4 .

44. Fairhurst CW, Hashinger DT, Twiggs SW. The effect of thermal history on porcelain expansion behavior. J Dent Res 1989;68: 1313-15.

45. DeHoff PH, Anusavice KJ. Tempering stresses in feldspathic porcelain. J Dent Res 1989;68: 134-38.

46. $h t t p: / / w w w$.webelements.com/webelements/properties/text/definitions/coeff-thermalexpansion.html

47. Nielsen JP, Tuccillo JJ. Interfacial stress in porcelain bodies bonded to metal prosthetic restorations. J Biomed Mat Res 1972;6:395-404.

48. Lenz J, Kessel S. Thermal stresses in metal-ceramic specimens for the ISO crack initiation test (three-point flexure bond test). Dent Mater 1998;14:277-80.

49. Mackert JR, Ringle RD, Parry EE, Evans AL, Fairhurst CW. The relationship between oxide adherence and porcelain-metal bonding. J Dent Res 1988;67:474-8. 
50. Vickery RC, Badinelli LA. Nature of attachment forces in porcelain-gold systems. J Dent Res 1968;47:683-9.

51. King BW, Tripp HP, Duckworth WH. Nature of Adherence of Porcelain Enamels to Metals. J Am Ceram Soc 1959;42:504-525.

52. Pask JA, Fulrath RM, Fundamentals of glass-to-metal bonding: VIII, Nature of Wetting and Adherence. J Am Ceram Soc 1962;45:592-596.

53. http://www corrosion-doctors.org/HotCorrosion/Pilling. htmsiondoctors. org

54. Huang HH, Lin MC, Lee TH, Yang HW, Chen FL, Wu SC. Effect of chemical composition of $\mathrm{Ni}-\mathrm{Cr}$ dental casting alloys on the bonding characterization between porcelain and metal. J Oral Rehab 2005;32:206-12.

55. Warpeha WS, Goodkind RJ. Design and technique variables affecting fracture resistance of metal-ceramic restorations. J Prosthet Dent 1976;55: 291-8.

56. Graham JD, Johnson A, Wildgoose DG, Sharef MY, Cannanria G. The effect of surface treatment on the bond strength of anon-precious alloy-ceramic interface. Int J Prosthodont 1999;12:330-334.

57. Carpenter MA, Goodkind RJ. Effect of varying surface texture on bond strength of one semiprecious and one nonprecious ceramo-alloy. J Prosthet Dent 1979;42: 8695.

58. Jochen DG, Caputo AA, Matyas J. Effect of metal surface treatment on ceramic bond strength. J Prosthet Dent 1986;55:186-188.

59. Cai Z, Bunce N, Nunn ME, Okabe T. Porcelain adherence to dental cast CP titanium: effects of surface modifications. Biomaterials 2001;22:979-986.

60. International Organization for Standardisaziton: ISO standard no.9693: Dental porcelain fused to metal restorations, Geneva, Switzerland 1999.

61. Jochen DG, Caputo AA, Matyas J. Effect of opaque porcelain application on strength of bond to silver-palladium alloys. J Prosthet Dent 1990;63:414-41.

62. Caputo AA, Dunn B, Reisbick MH. A flexural method for evaluation of metal-ceramic bond strengths. J Dent Res 1977;56:1501-06.

63. Lorenzana RE, Chambless LA, Marker VA, Staffanou RS. Bond strengths of highpalladium content alloys. J Prosthet Dent. 1990;64:677-80.

64. Chi $T$, Ballinger $T$, Olds R, Zecchino $M$ Surface texture analysis using dektak stylus profilers. www. veeco.com 2004

65. Anusavice KJ, Dehoff PH, Fairhurst CW. Comparative evaluation of ceramic-metal bond tests using finite element stress analysis. J Dent Res 1980; 59:608-13. 
66. Hammad IA, Talic YF. Designs of bond strength tests for metal-ceramic complexes: review of the literature. J Prosthet Dent 1996;75:602-8.

67. Lenz J, Schwarz S, Schwickerath H, Sperner F, Schäfer A. Bond strength of metalceramic systems in three-point flexure bond test. J Appl Biomat 1995; 6:55-64.

68. Quinn GD, Morrell R Design Data for Engineering Ceramics: A review of the flexure test. J Am Ceram Soc 1991;74: 2037-66.

69. Personal Communication

70. Rosensteil SF, Denry IL, Zhu W, Gupta PK, Van der Sluys RA. Fluoroalkylethyl silane coating as a moisture barrier for dental ceramics. J Biomed Mater Res 1993;27:415-417.

71. McLean JW. High Stress Ceramics. Quintessence Int. 1987;18:97-106.

72. Bertolotti RL. Porcelain to metal bonding and compatability. In McLean(ed) Dent Ceramics: Proceedings of the First International Symposium on Ceramics. Chicago, IL Quintessence Pub Co. 1983 p 415. 


\section{List of Figures}

Fig. 1 Worn Dentition opposing exposed opaque porcelain. a, b, c.

Fig. 2 Diagram of specimen geometry

Fig. 3 Measuring strips for porcelain application

Fig. $4 \quad$ Calibration of porcelain furnaces

Fig. $5 \quad$ Oxidation firing of specimens

Fig. 6 Dektak 8 profilometer

Fig. $7 \quad$ Porcelains used for specimen fabrication. $a, b$

Fig. 8 Opaque firing of specimens

Fig. $9 \quad$ Firing of dentin (body) specimens

Fig. 10 Flow Chart of specimen preparation

Fig. 11 Specimen placed in mechanical testing apparatus

Fig. 12 Example of load-versus-displacement curve generated

Fig. 13 Microphone adjacent to testing apparatus

Fig. $14 \quad$ Example of recording graph with all recorded noise amplitudes present

Fig. 15 Correspondence of noise amplitude versus time with flexure loadversus-displacement curve

Fig. $16 \quad$ Various SEM images of failure modes

Fig. 17 Example of metal and body porcelain adhesive failure SEM

Fig. 18 Example of cohesive failure within porcelain SEM

Fig. 19 FEM used in pilot study 


\section{List of Tables}

Table I

Table II

Table III

Table IV

Table V

Table VI

Table VII

Table VIII
Alloy composition

Oxidation firing schedules for alloys

Firing schedule for Porcelains

Overall results

3-way ANOVA results for debonding/crack initiation strength

$\mathrm{Ra}(\AA)$ values and debonding strength/crack initiation strength values $(\mathrm{MPa})$ for each alloy system

Mean (SD) debonding strength/crack initiation strength values $(\mathrm{MPa})$ for each metal-ceramic system

Mean (SD) debonding strength/crack initiation strength values (MPa) for each metal and opaque system, irrespective of porcelain type 


\section{List of Graphs}

Graph 1

K-value determinant rom ISO 9693:1999 (E)

Graph 2

Mean (SD) debonding strength/crack initiation strength values for each metal ceramic system

Graph 3

Dispersion of specimen values, bonding strength ( $\mathrm{MPa}$ ) by $\operatorname{Ra}(\AA)$ 


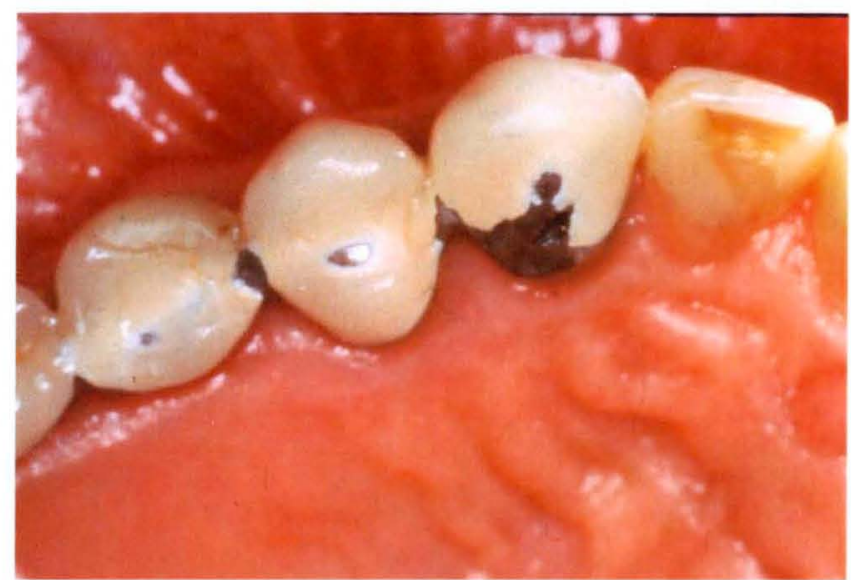

A

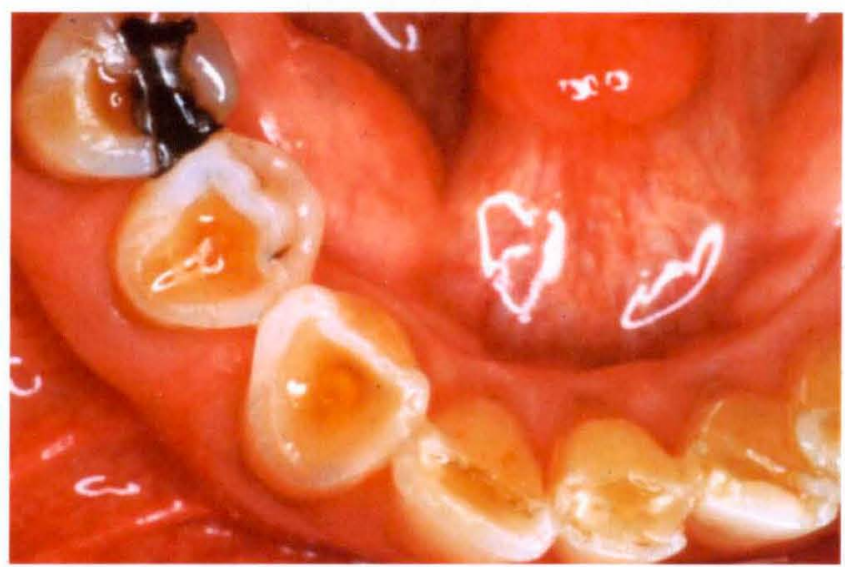

B

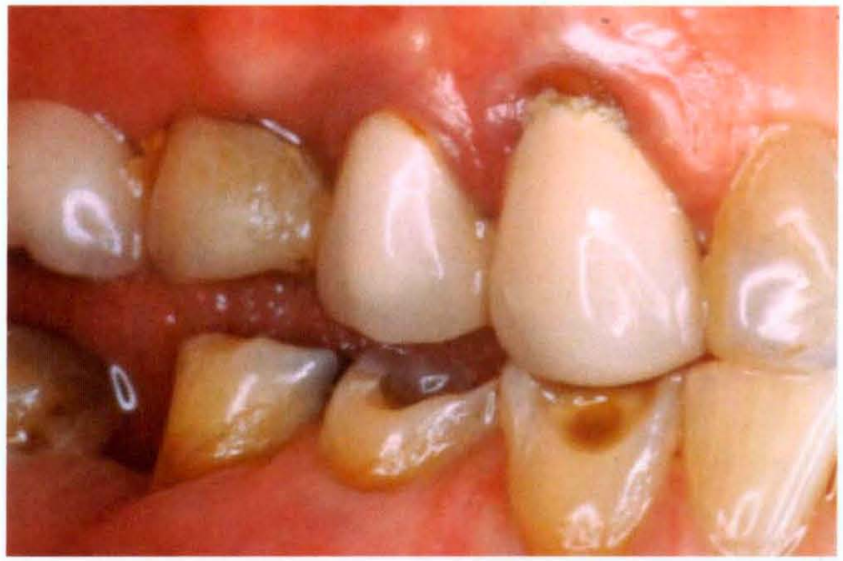

C

Figure 1. Worn dentition opposing exposed opaque porcelain. A, Exposed opaque porcelain on maxillary metal-ceramic restorations. B, Occlusal view of opposing mandibular dentition. C, Facial view of dentition in occlusion. 


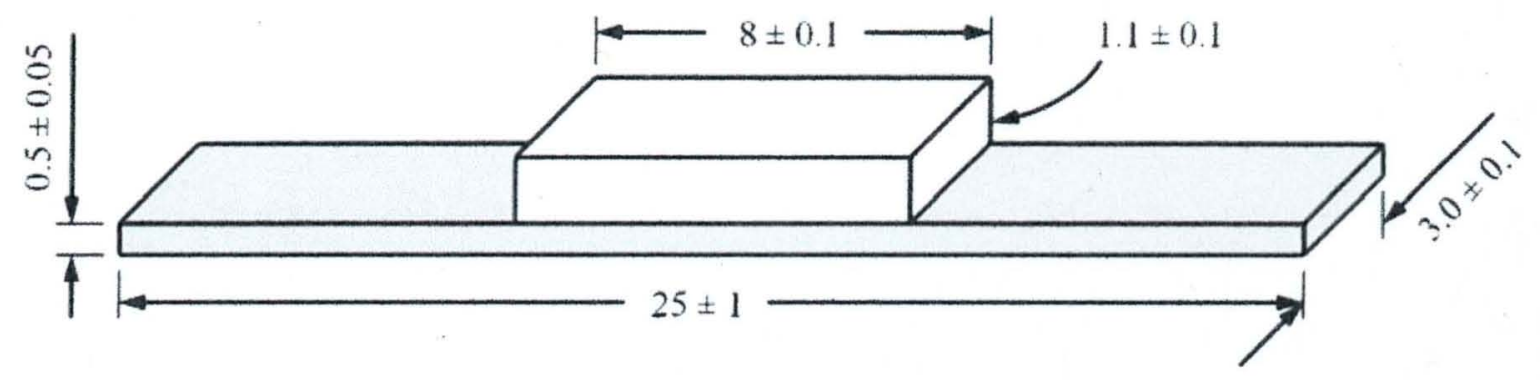

Figure 2. Diagram of specimen geometry. 


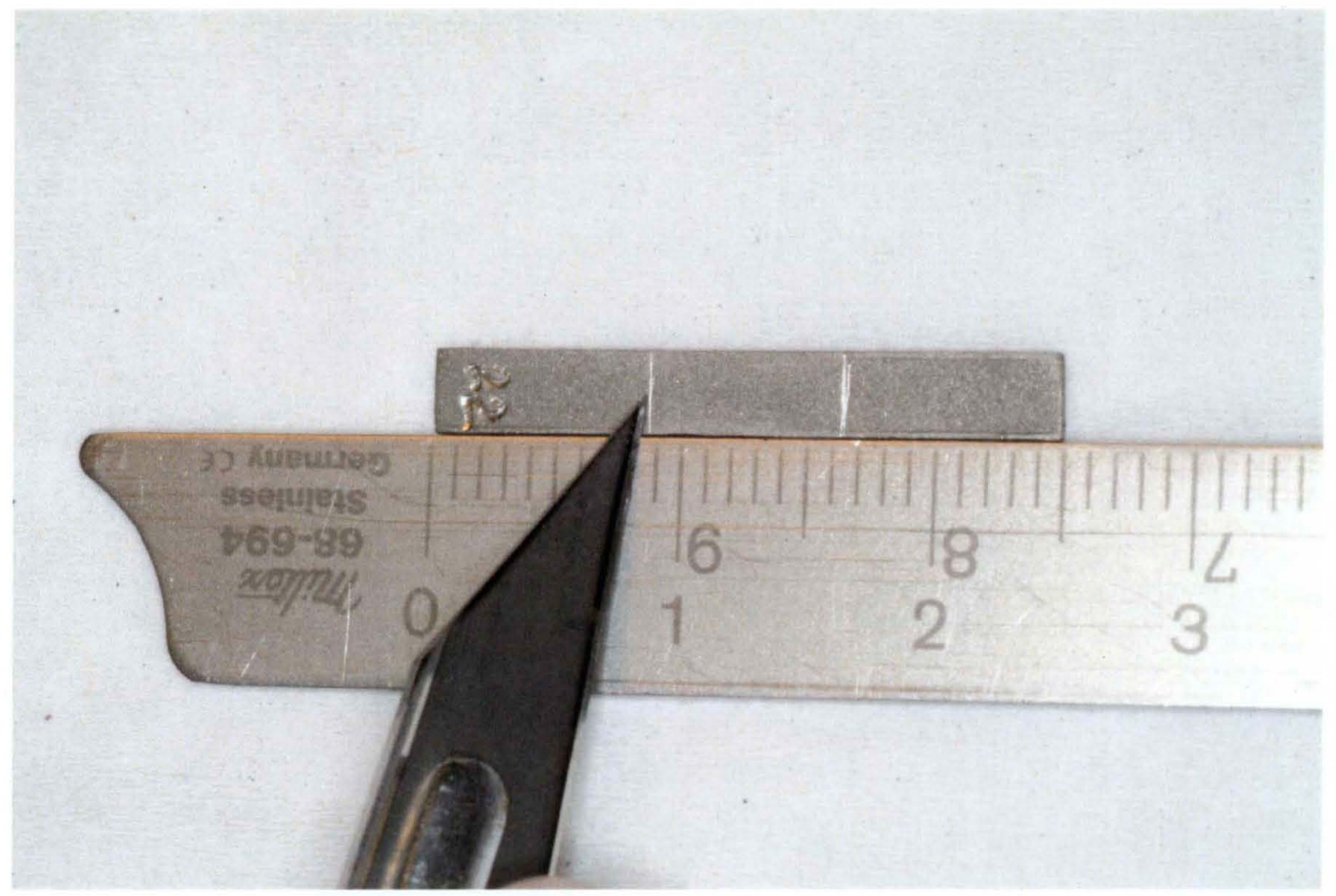

Figure 3. Measuring strips for porcelain application. 

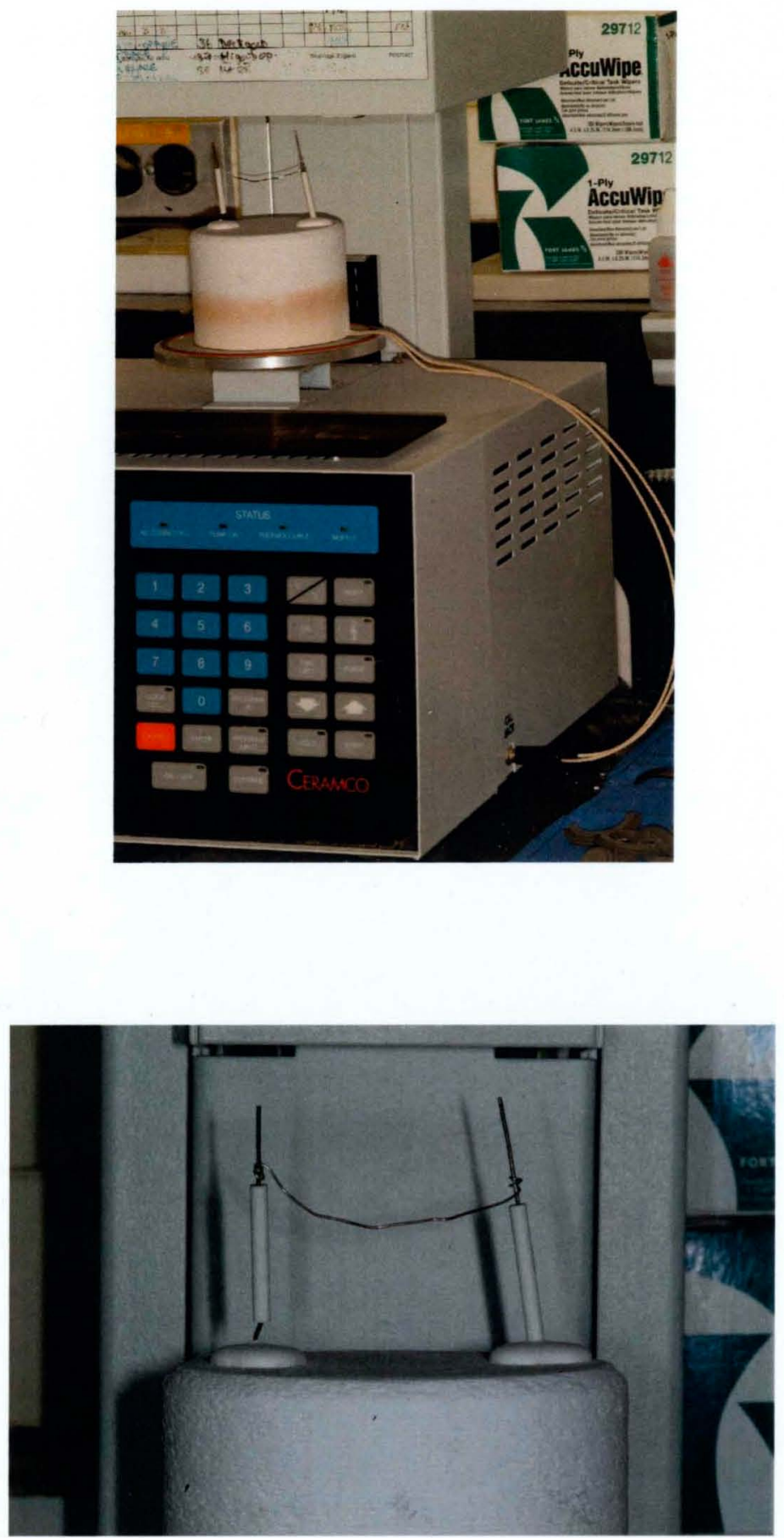

Figure 4. Calibration of porcelain furnaces 

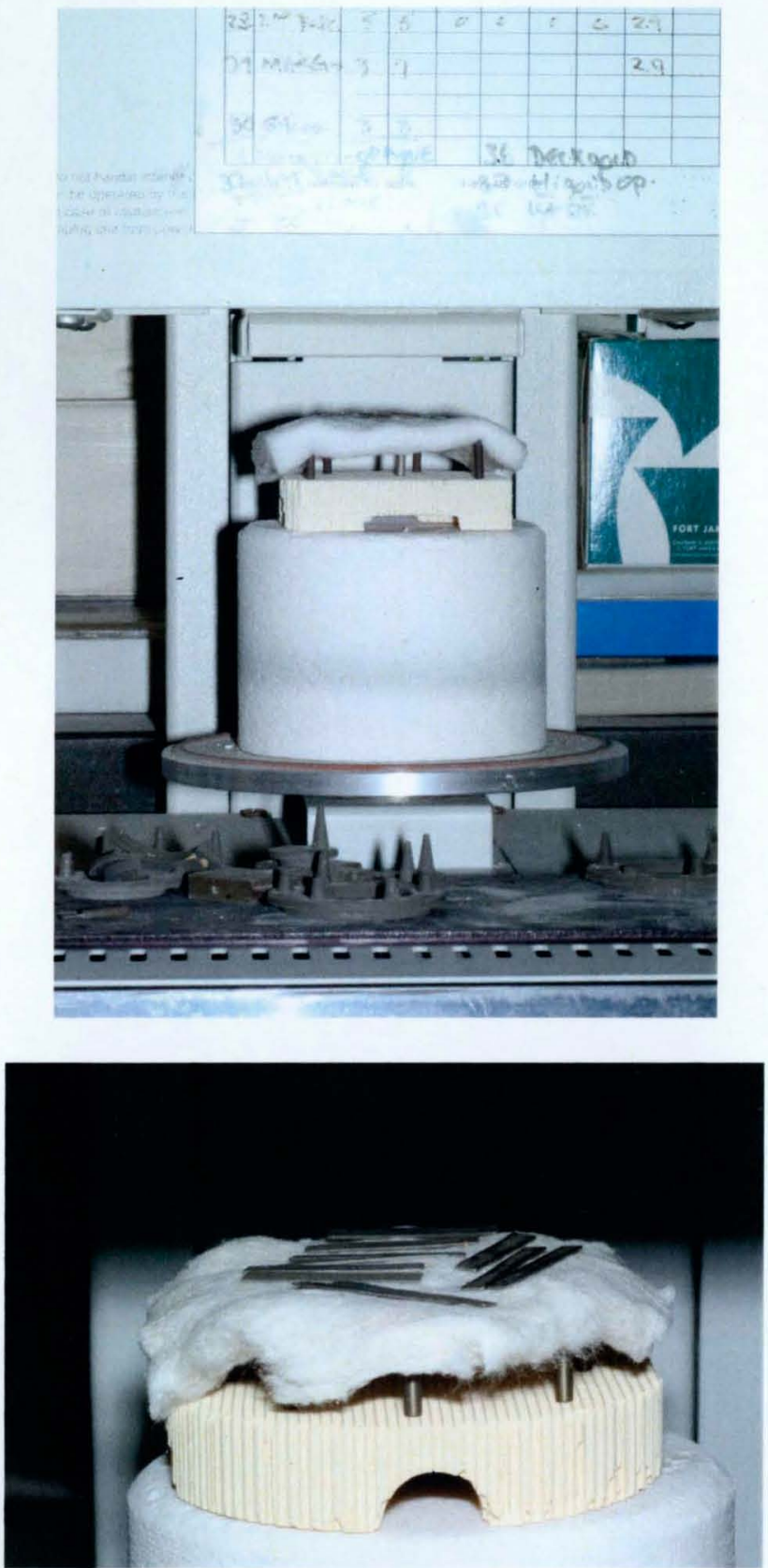

Figure 5. Oxidation firing of specimens on suspended platform 

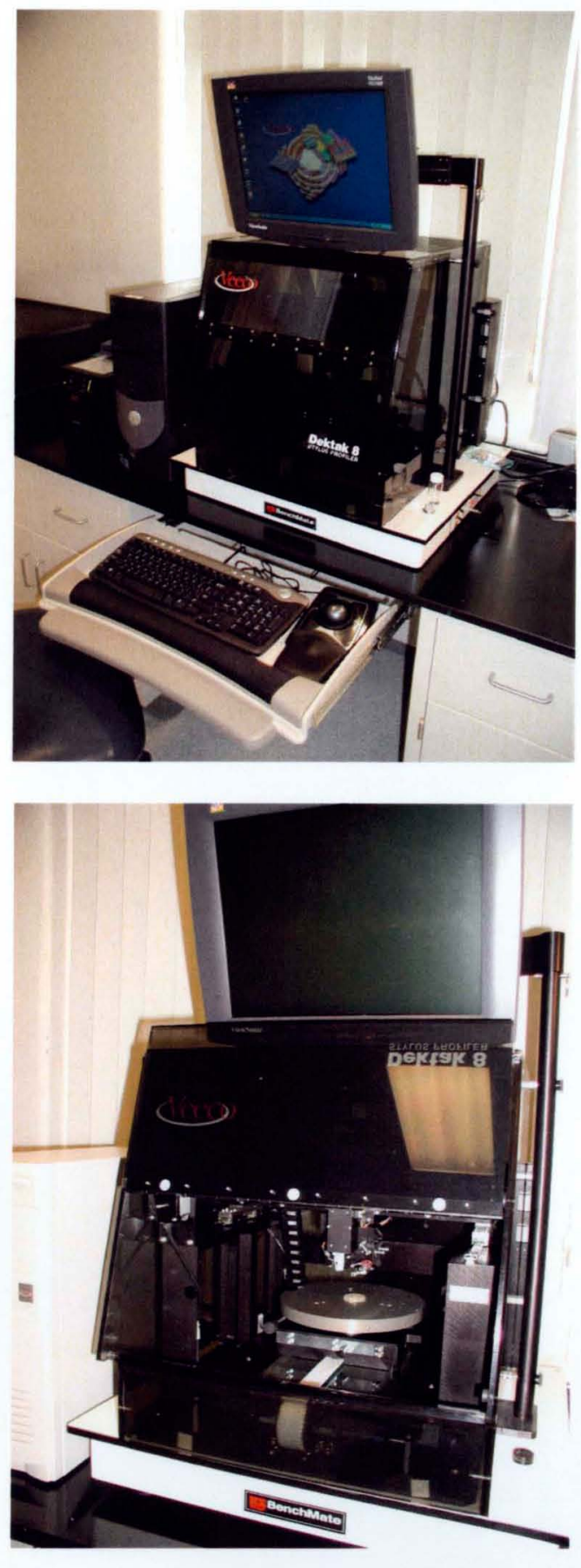

Figure 6. Dektak 8 profilometer 


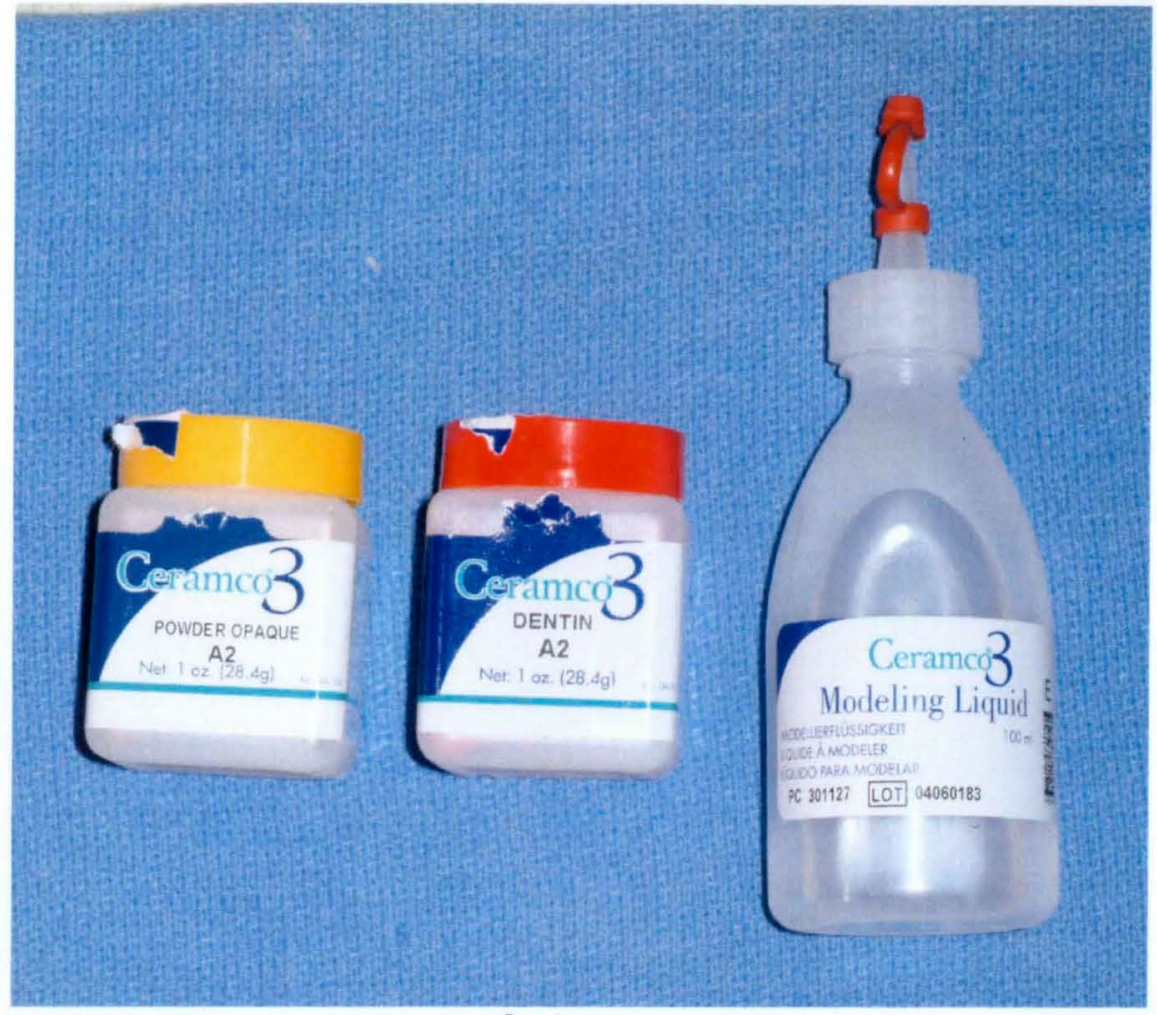

A

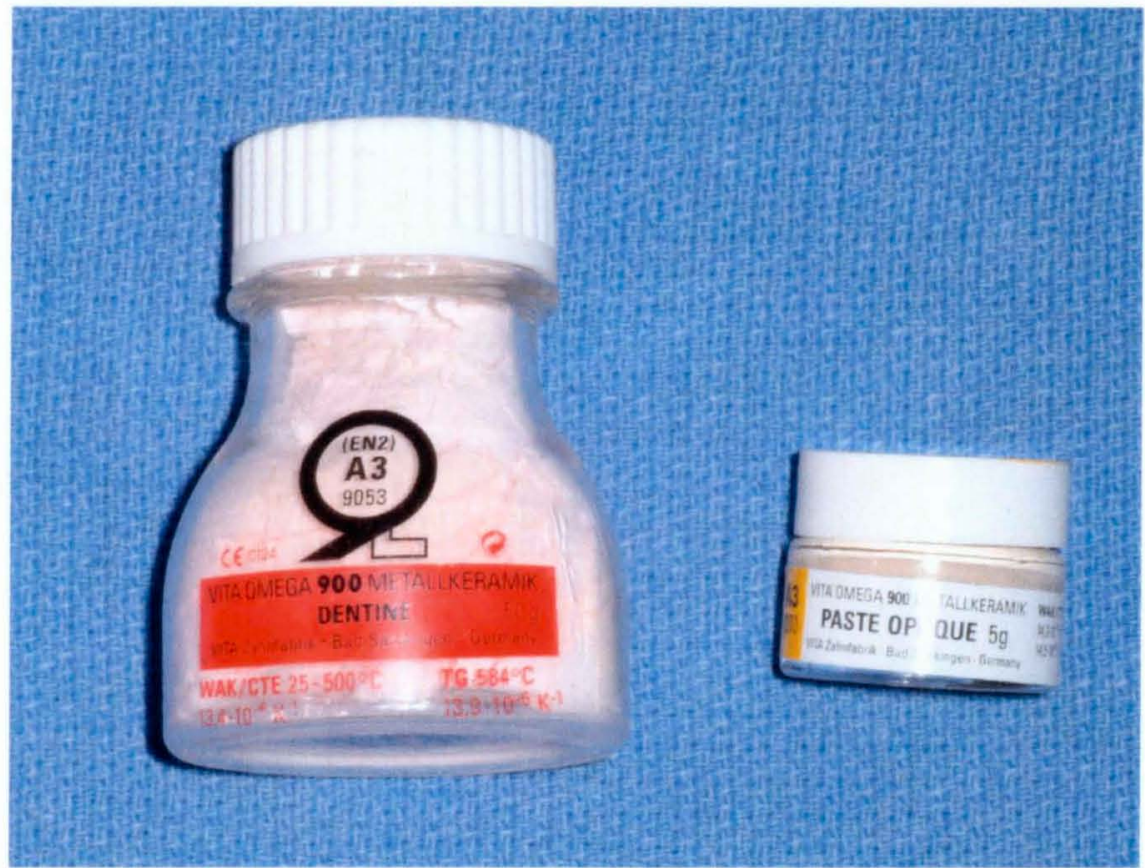

B

Figure 7. Porcelains used for specimen fabrication. A, Ceramco 3 body and opaque powder. B, Vita 900 body and paste opaque. 

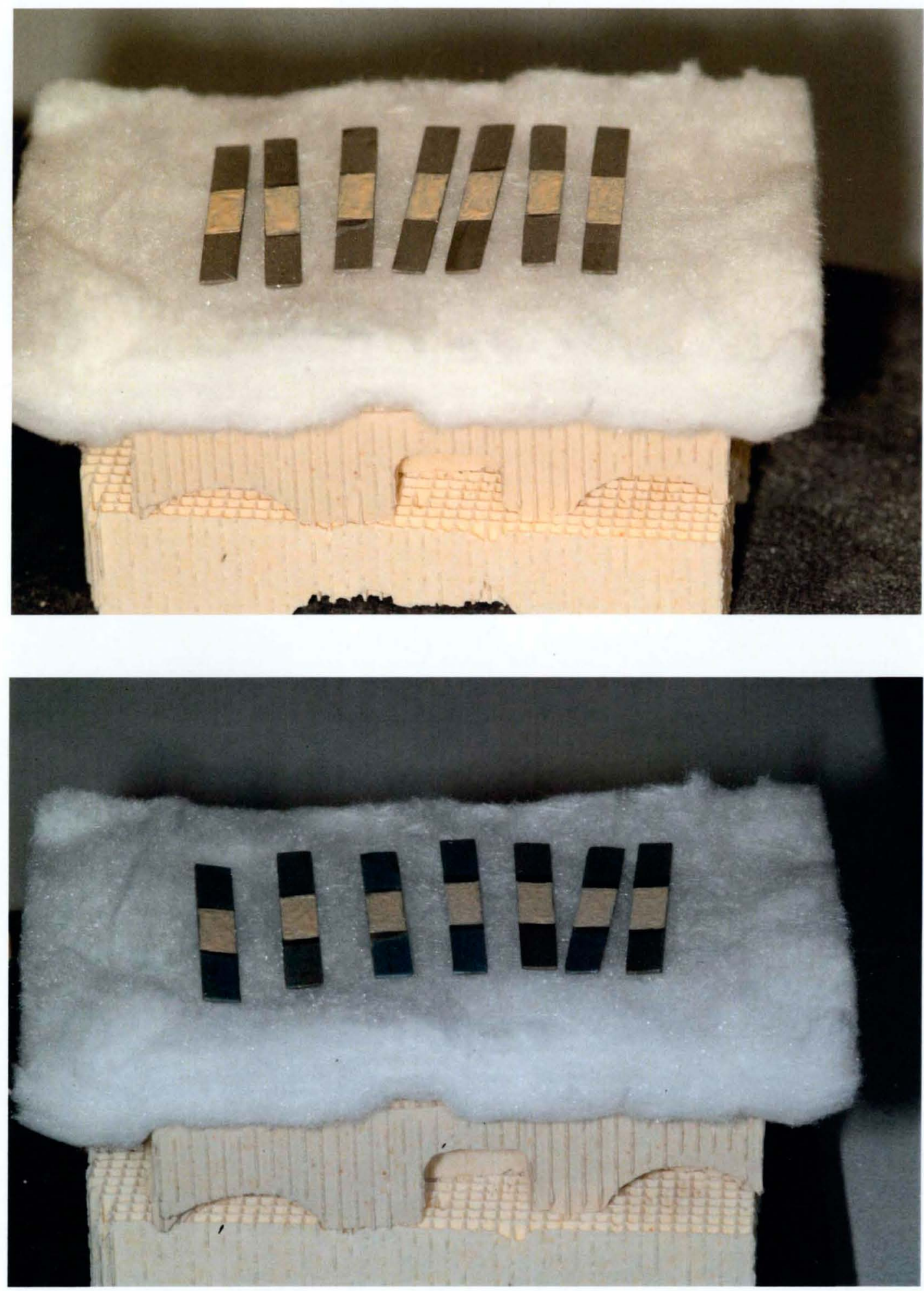

Figure 8. Opaque firing of specimens. 

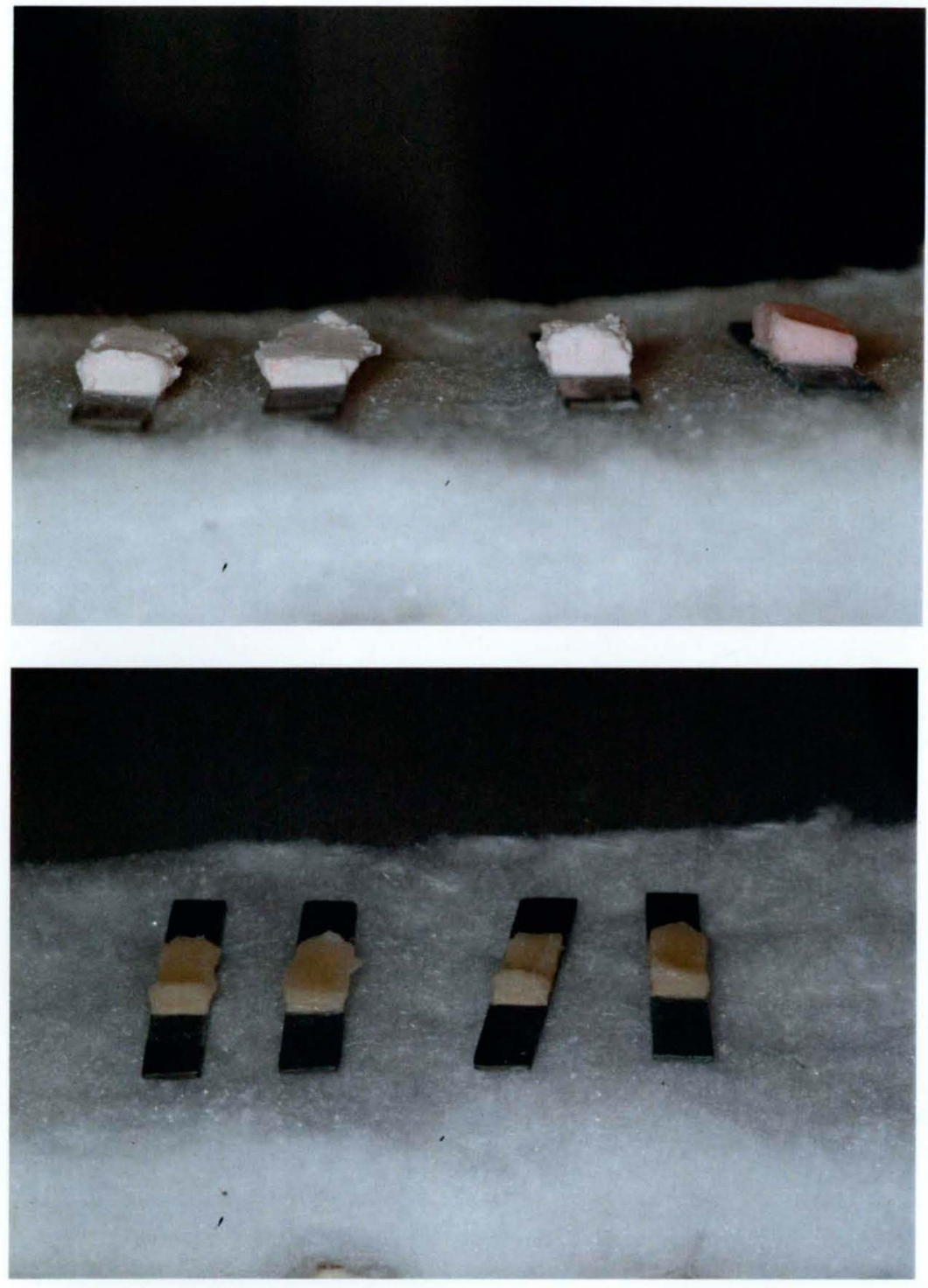

Figure 9. Firing of dentin (body) porcelain on specimens. 

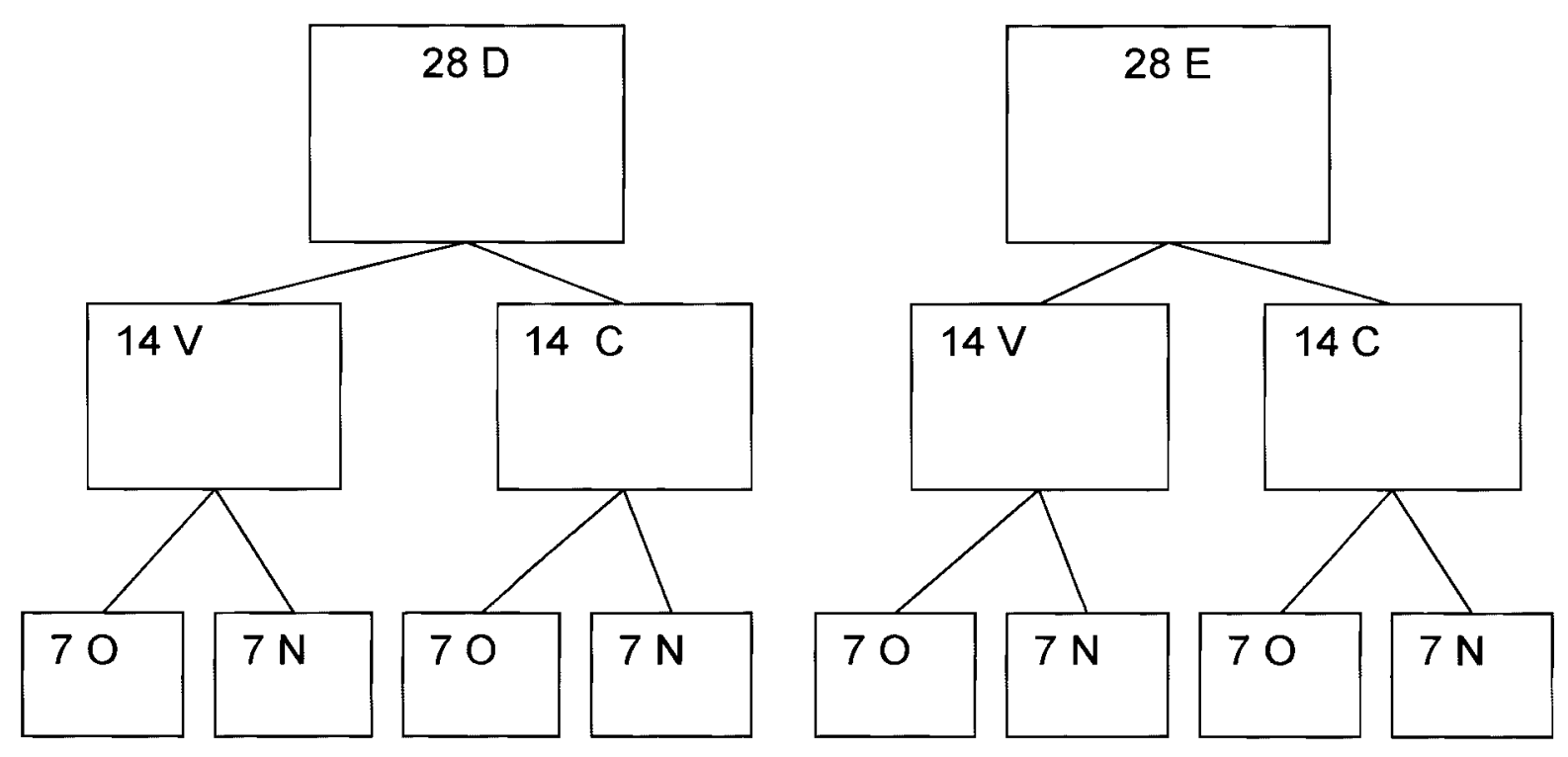

Figure 10. Flow chart of specimen preparation. D, Duceranium U alloy. E, Encore alloy. V, Vita 900 porcelain system. C, Ceramco 3 porcelain system. $\mathbf{O}$, Opaque added. N, No opaque added 


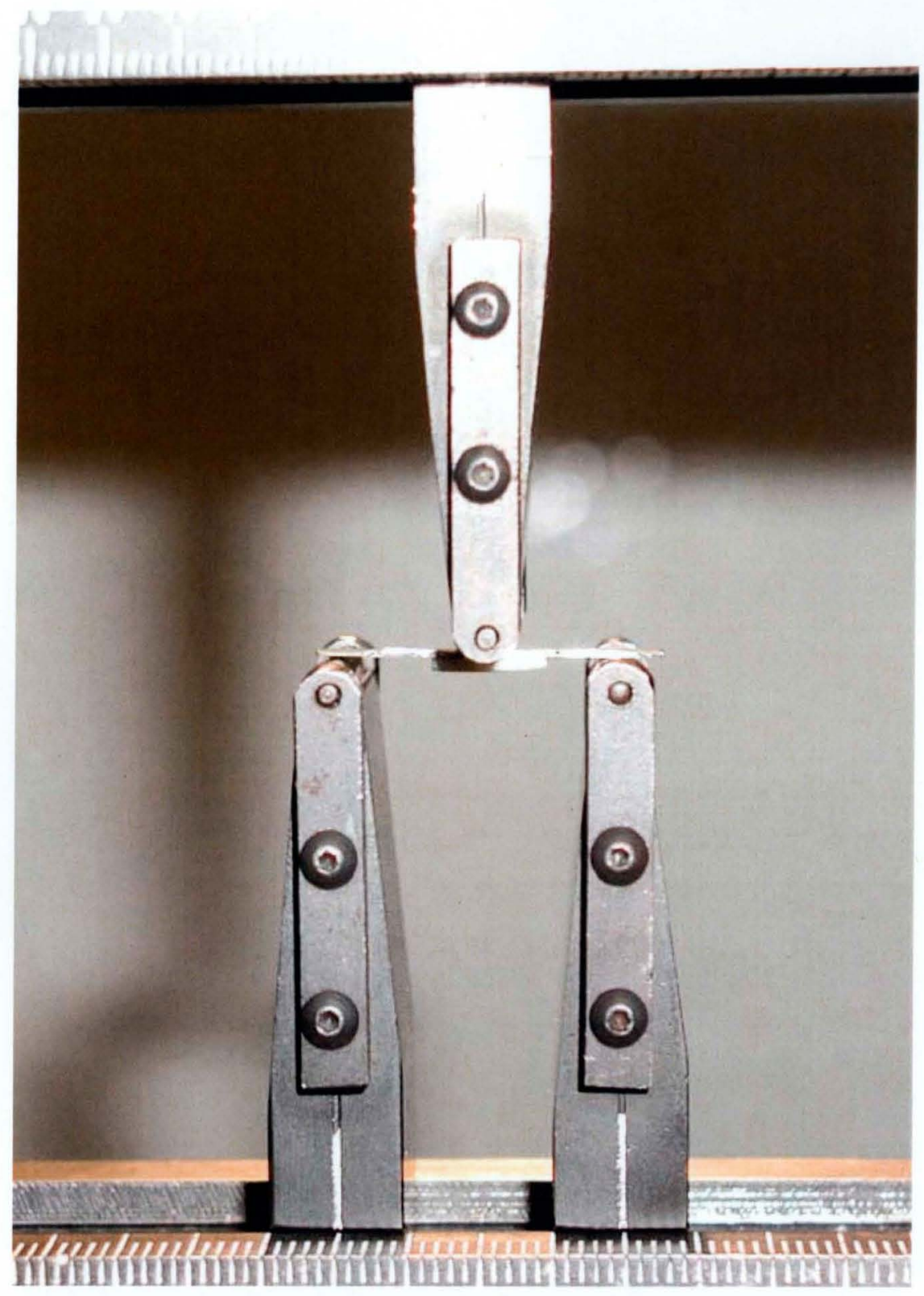

Figure 11. Specimen placed in mechanical testing device. 


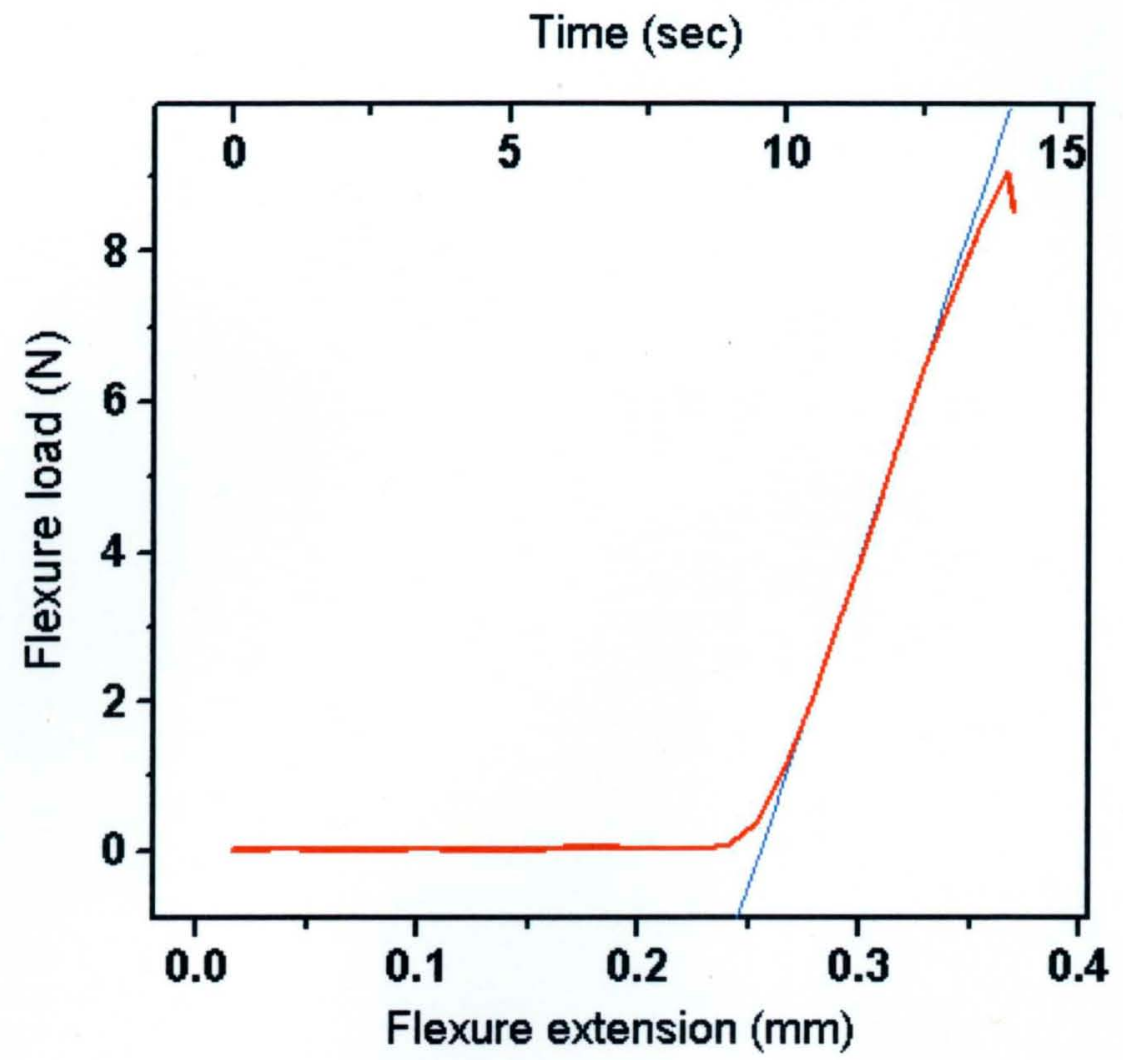

Figure 12. Example of load-versus-displacement curve generated. Blue tangential line represents departure from linearity. 


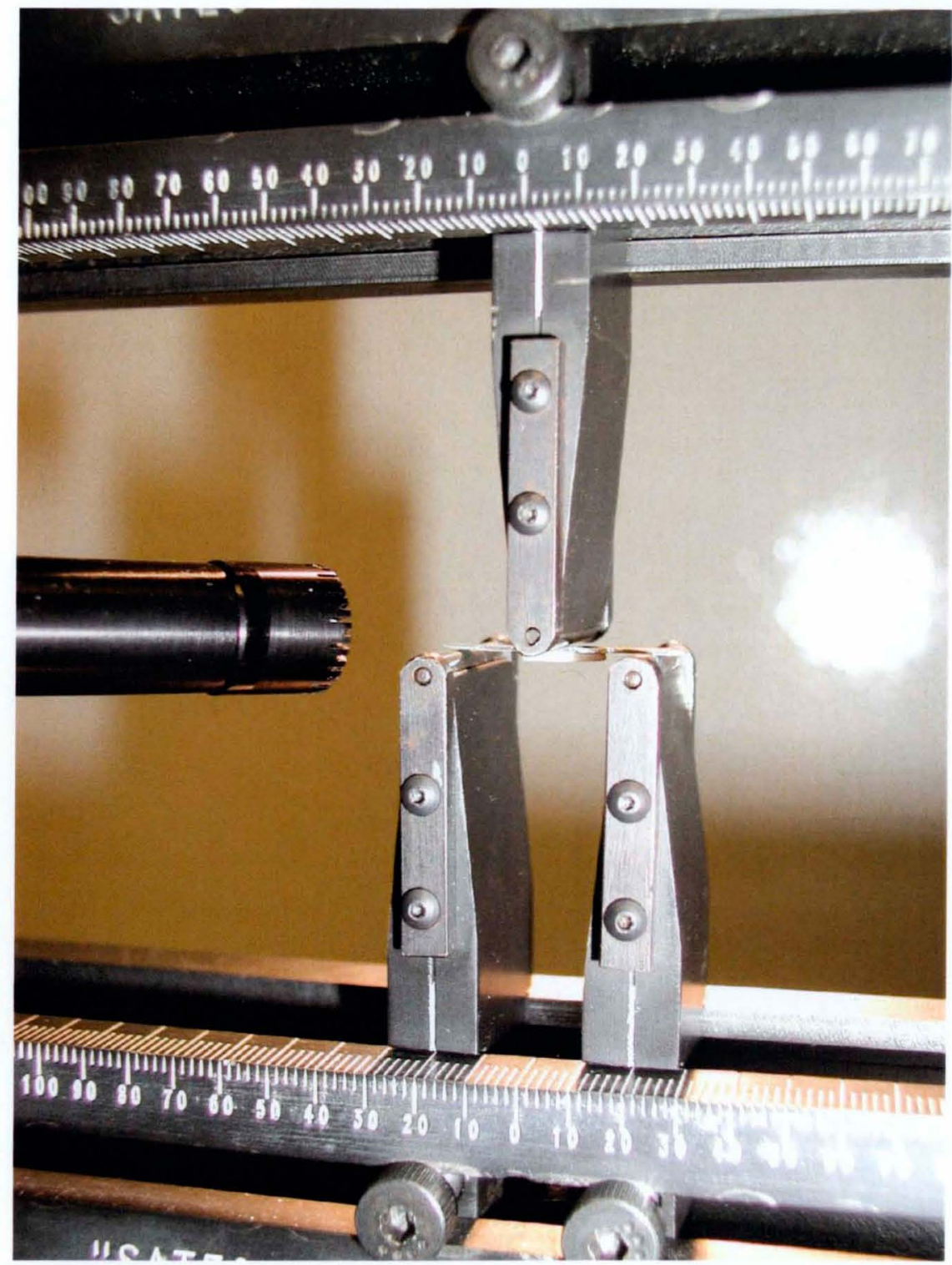

Figure 13. Microphone adjacent to testing apparatus. 


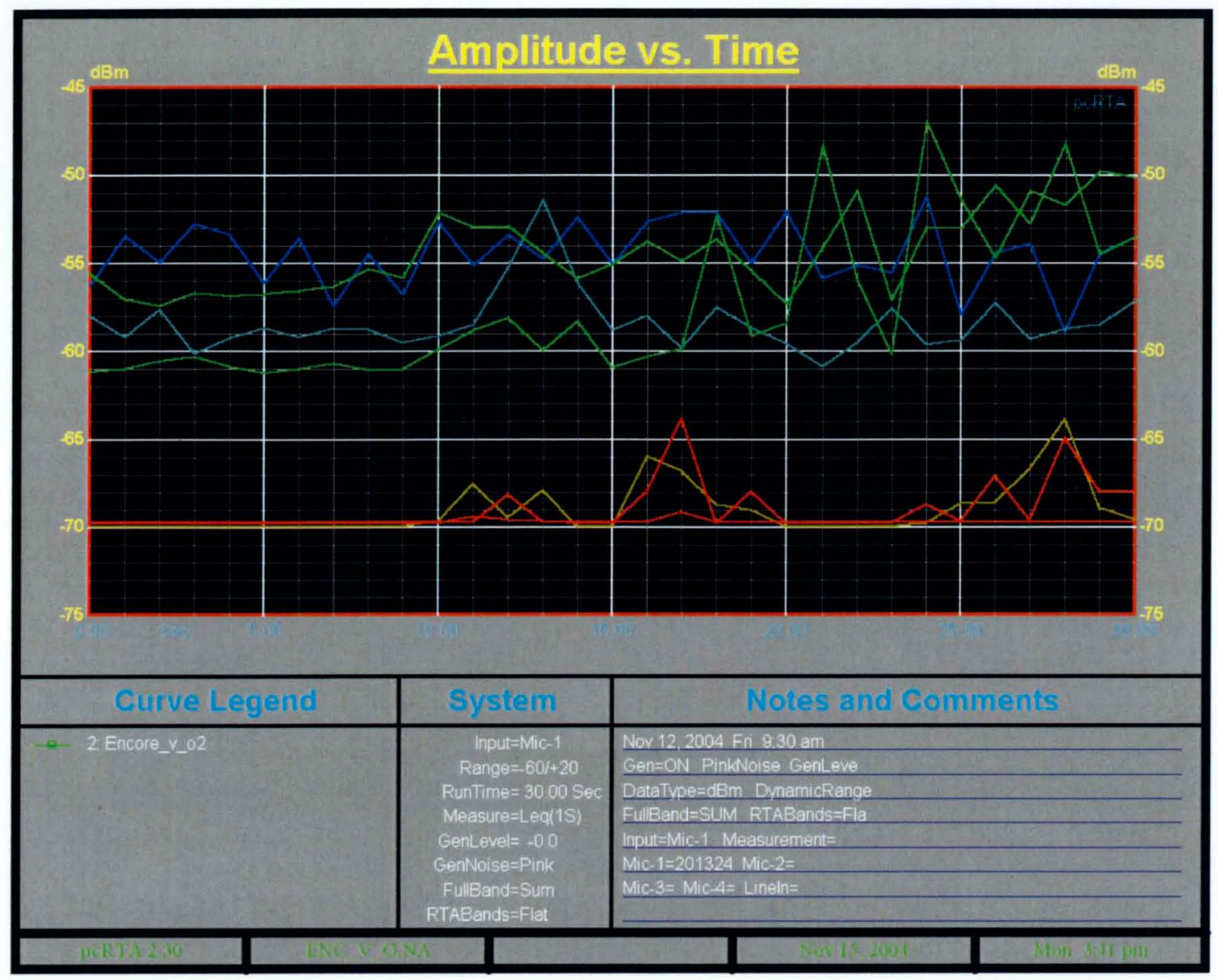

Figure 14. Example of recording graph with all recorded frequencies present. 
A

Amplitude vs. Time

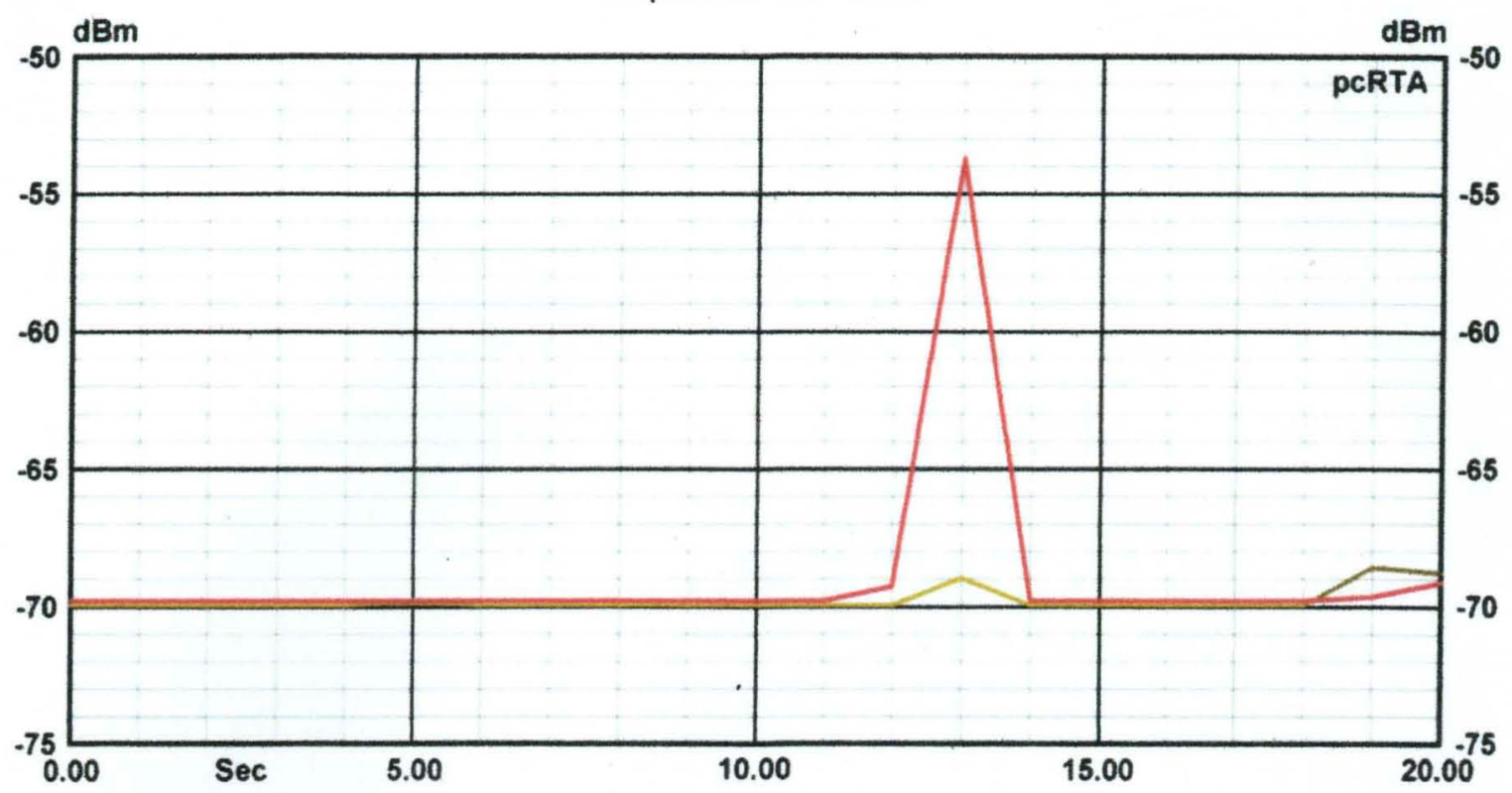

B

Time (sec)

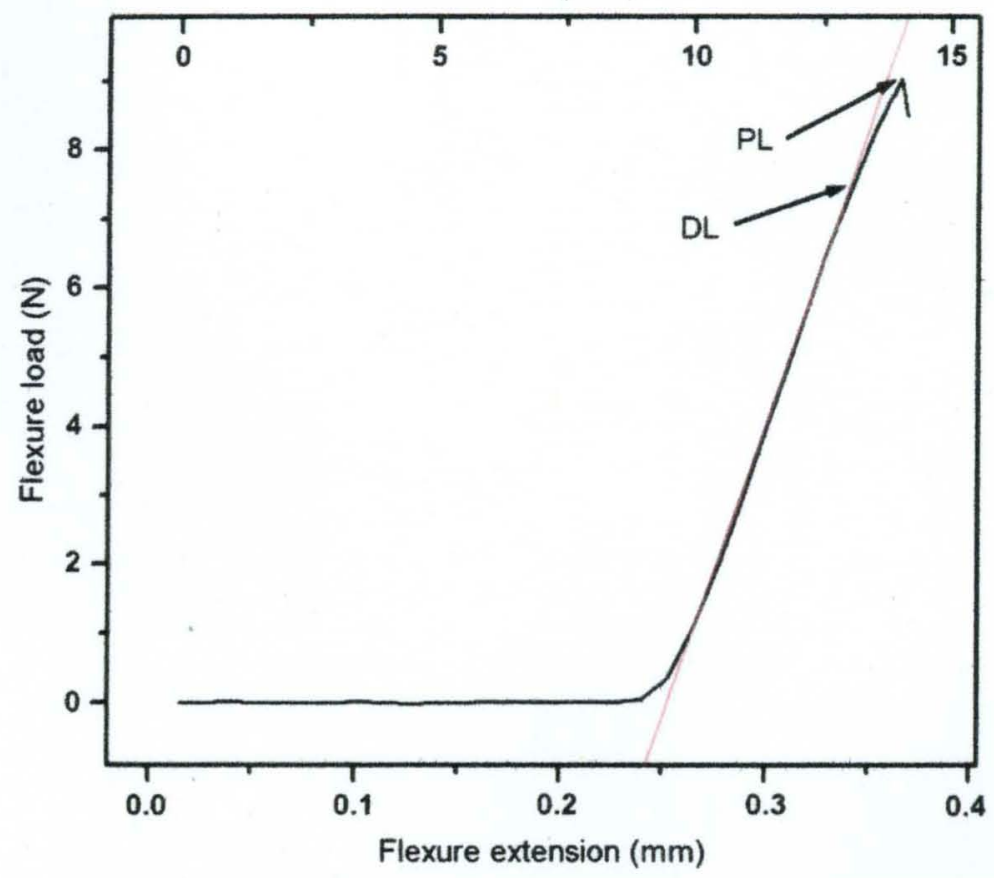

Figure 15. Correspondence of noise amplitude versus time with flexure loadversus-displacement curve. A, $5 \mathrm{kHz}$ (brown) and $10 \mathrm{kHz}$ (red) frequencies were measured over time, and peak was observed in both curves at 13 seconds. $\mathbf{B}$, Departure from linearity (DL) for flexure load-versus-displacement curve occurred at 13 seconds and at a load of $7.05 \mathrm{~N}$. Peak load $(\mathrm{PL})$ recorded during testing was $9.05 \mathrm{~N}$. 

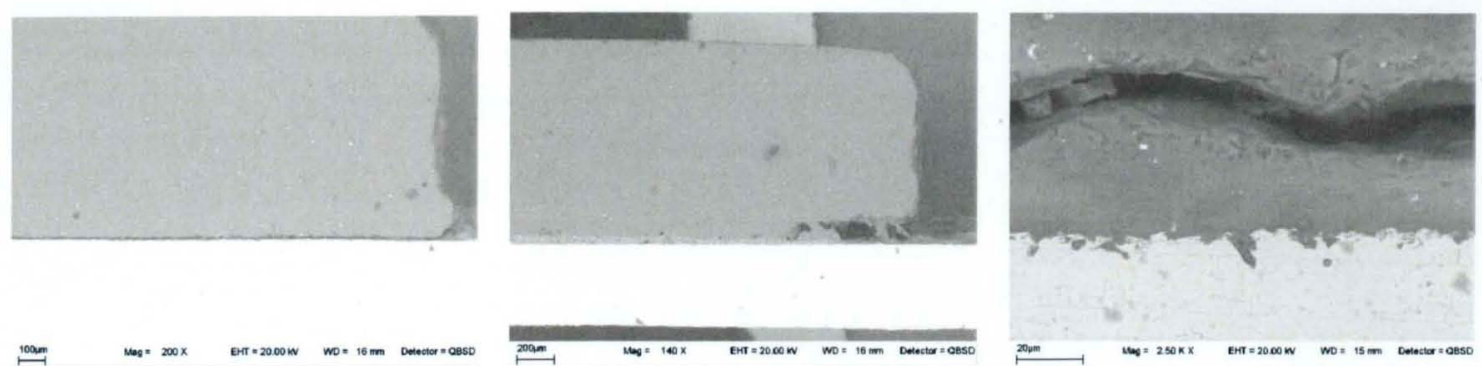

$+$

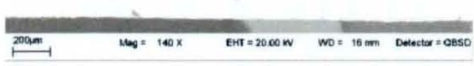

xom
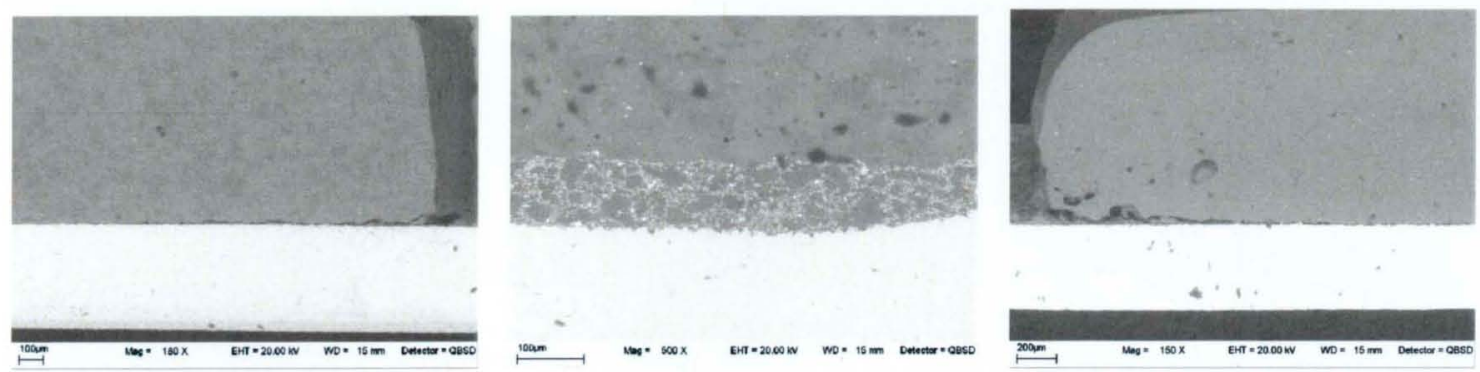

$\stackrel{100 \mathrm{~m}}{\longmapsto}$

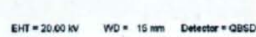
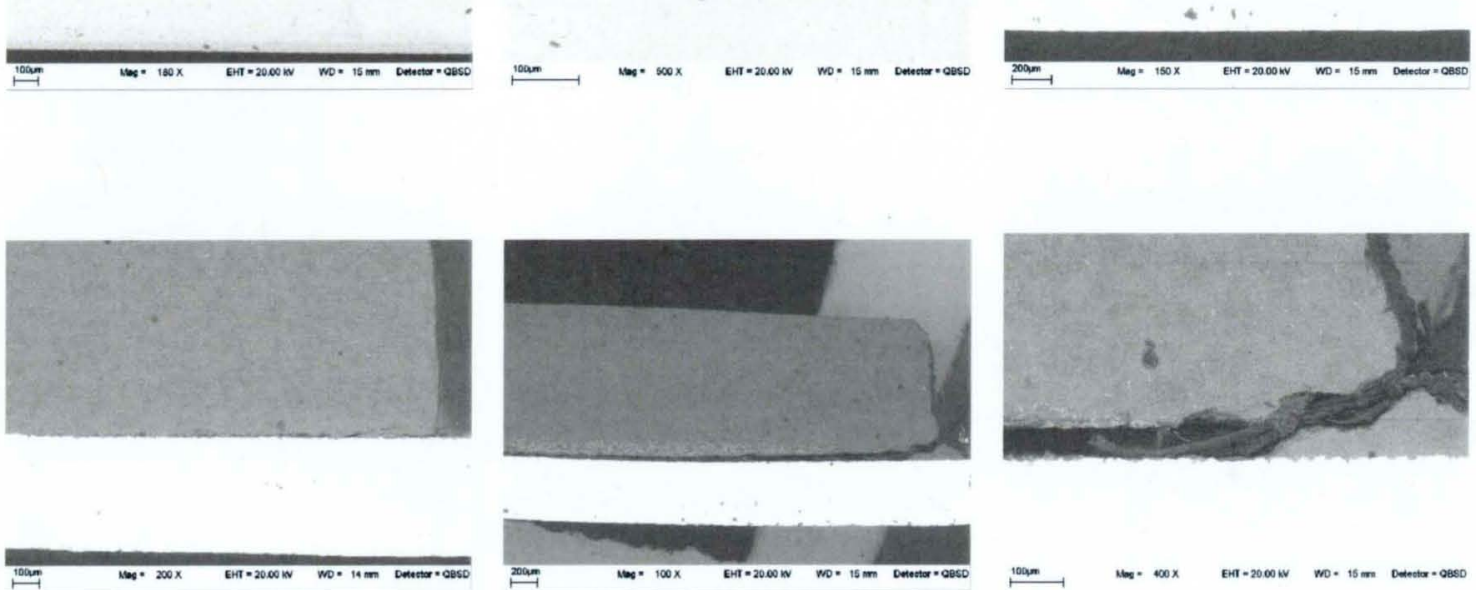

$\stackrel{\log m}{\longmapsto}$

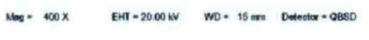

Figure 16. Various SEM images of failure modes. 


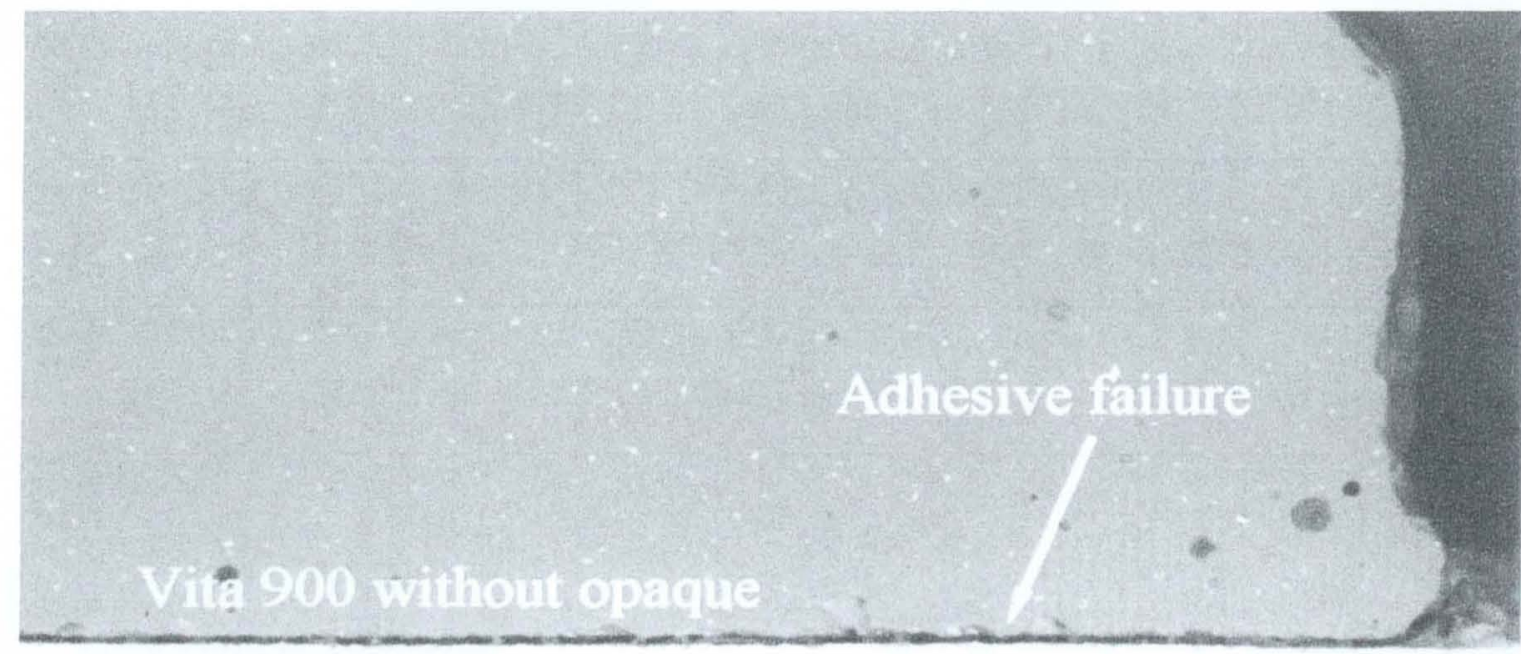

\section{Duceranium U}

$100 \mu \mathrm{m}$

$\operatorname{Mag}=200 \times$

$E H T=20.00 \mathrm{kV}$

$W D=16 \mathrm{~mm}$ Detector $=$ QBSD

Figure 17. Example of metal and body porcelain adhesive failure. Original magnification $\times 200$. 


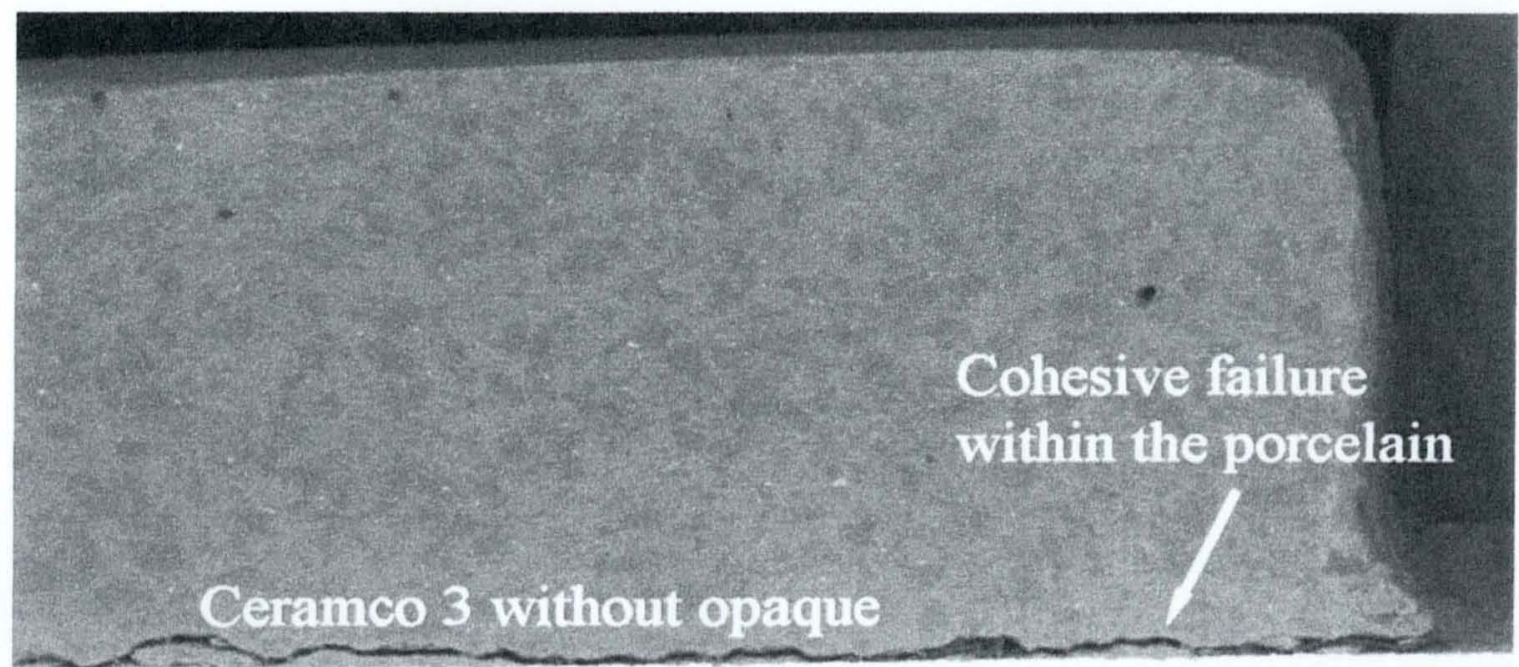

\section{Duceranium U}

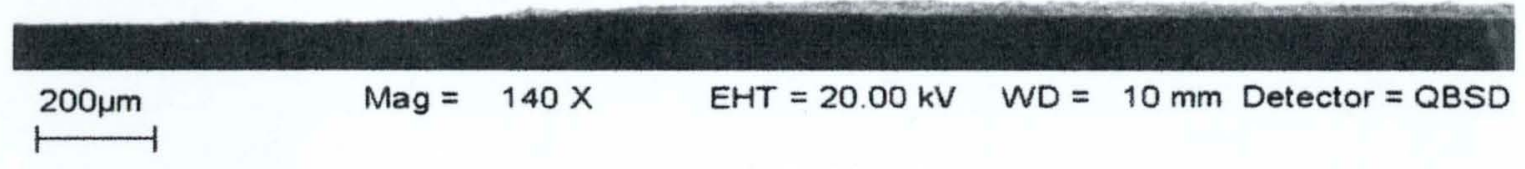

Figure 18. Example of cohesive failure within porcelain. Original magnification x 140 . 


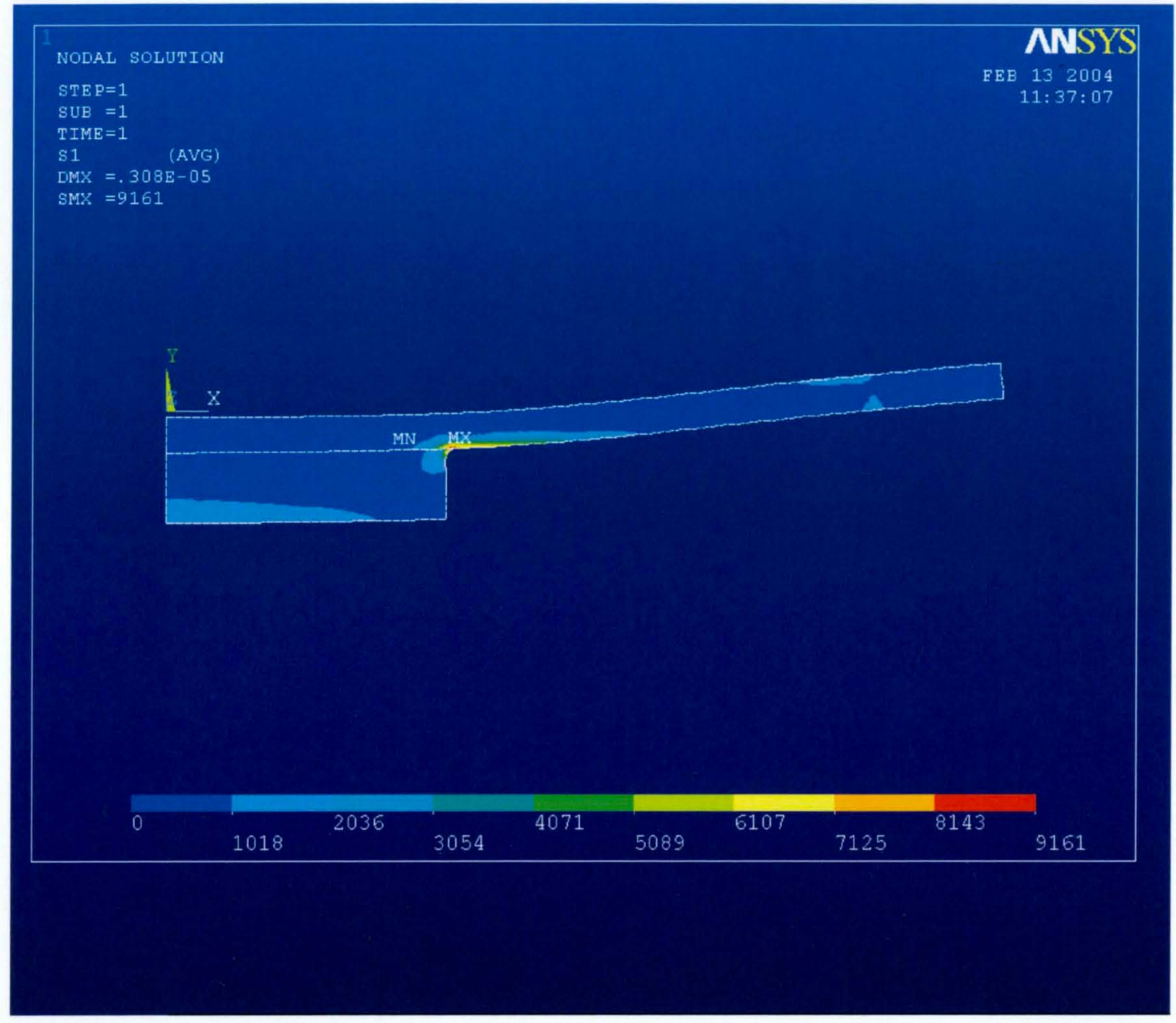

Figure 19. FEM used in pilot study 
Table I. Alloy Composition (Wt. \%)

\begin{tabular}{llll}
\hline \multicolumn{2}{l}{ Duceranium U } & \multicolumn{2}{l}{ Encore } \\
\hline $\mathrm{Ni}$ & 59.0 & $\mathrm{Au}$ & 48.0 \\
$\mathrm{Cr}$ & 21.5 & $\mathrm{Pd}$ & 40.0 \\
$\mathrm{Mo}$ & 4.5 & $\mathrm{Zn}$ & 4.35 \\
$\mathrm{~W}$ & 5.0 & $\mathrm{Re}$ & 0.05 \\
$\mathrm{Mn}$ & 0.4 & $\mathrm{In}$ & 3.75 \\
$\mathrm{Fe}$ & 3.5 & $\mathrm{Sn}$ & 3.85 \\
$\mathrm{Co}$ & 0.5 & & \\
$\mathrm{Cu}$ & 1.5 & & \\
$\mathrm{Si}$ & 0.8 & & \\
$\mathrm{Nb}$ & 3.2 & & \\
$\mathrm{C}$ & 0.1 & & \\
\hline
\end{tabular}


Table II. Oxidation firing schedules for Alloys $\left({ }^{\circ} \mathrm{C}\right)$

\begin{tabular}{lcl}
\hline Procedure & Duceranium U & Encore \\
\hline Entry temp & 650 & 650 \\
High temp & 1010 & 1038 \\
Heat Rate & $55 /$ min & $55 /$ min \\
High Temp Hold & 5 min vacuum & Omin vacuum \\
\hline
\end{tabular}


Table III. a. Firing schedule for Vita 900 and b. Ceramco 3 Porcelains $\left({ }^{\circ} \mathrm{C}\right)$

a.

\begin{tabular}{lcccccc}
\hline Vita 900 & $\begin{array}{c}\text { Pre-Drying } \\
\text { Temp }\end{array}$ & $\begin{array}{c}\text { Hold } \\
(\mathrm{min})\end{array}$ & Increase & $\begin{array}{c}\text { Temp. } \\
\text { Approx. }\end{array}$ & $\begin{array}{c}\text { Hold } \\
(\mathrm{min})\end{array}$ & Vac \\
\hline 1st Opaque Firing & 500 & 6 & 6 & 900 & 3 & 6 \\
2nd Opaque Firing & 500 & 6 & 6 & 900 & 2 & 6 \\
Dentin Firing & 600 & 6 & 6 & 900 & 1 & 6 \\
2nd Dentin Firing & 600 & 6 & 6 & 890 & 1 & 6 \\
3rd Dentin Firing & 600 & 6 & 6 & 890 & 1 & 6 \\
\hline
\end{tabular}

b.

\begin{tabular}{|c|c|c|c|c|c|c|c|c|c|c|c|c|}
\hline Ceramco 3 & Dry & $\begin{array}{l}\text { Pre- } \\
\text { heat }\end{array}$ & $\begin{array}{l}\text { Vac } \\
\text { hold }\end{array}$ & $\begin{array}{l}\text { HiT } \\
\text { hold }\end{array}$ & Hold & $\begin{array}{l}c \\
\text { o } \\
\text { ol }\end{array}$ & $\begin{array}{l}\text { Vac } \\
\text { set } \\
\text { point } \\
\text { (Hg) }\end{array}$ & Idle & $\stackrel{\text { High }}{T}$ & $\begin{array}{l}\text { Vac } \\
\text { Start }\end{array}$ & $\begin{array}{l}\text { Vac } \\
\text { Stop }\end{array}$ & $\begin{array}{l}\text { Rate } \\
\text { C'min }\end{array}$ \\
\hline Opaque & 5 & 3 & 0 & 0 & 0 & 0 & 29 & 650 & 970 & 650 & 970 & 70 \\
\hline Dentin & 5 & 5 & 0 & 0 & 0 & 0 & 29 & 650 & 960 & 650 & 960 & 55 \\
\hline
\end{tabular}


Table IV. Overall results for each metal-ceramic bar tested.

\begin{tabular}{|c|c|c|c|c|c|c|c|c|c|}
\hline Metal & Porcelain & Opaque & $F_{\text {fail }} N$ & $\mathrm{~K}$ & Em Gpa & Trial No. & Spec. No & $\mathrm{MPa}$ & $\operatorname{Ra}(\AA)$ \\
\hline$D$ & $\mathrm{~V}$ & 0 & 8.05 & 4.05 & 178 & 1 & 56 & 32.6025 & 32655 \\
\hline$D$ & v & 0 & 7.43 & 4.05 & 178 & 2 & 41 & 30.0915 & 33730 \\
\hline$D$ & v & 0 & 6.65 & 4.05 & 178 & 3 & 27 & 26.9325 & 62512 \\
\hline $\mathrm{D}$ & $\mathrm{V}$ & 0 & 6.66 & 4.05 & 178 & 4 & 15 & 26.973 & 41322 \\
\hline $\mathrm{D}$ & V & 0 & 5.86 & 4.05 & 178 & 5 & 9 & 23.733 & 43991 \\
\hline$D$ & V & 0 & 5.19 & 4.05 & 178 & 6 & 24 & 21.0195 & 50857 \\
\hline $\mathrm{D}$ & V & 0 & 5.36 & 4.05 & 178 & 7 & 3 & 21.708 & 40646 \\
\hline D & c & 0 & 7.16 & 4.05 & 178 & 1 & 51 & 28.998 & 62769 \\
\hline D & C & 0 & 5.79 & 4.05 & 178 & 2 & 30 & 23.4495 & 39674 \\
\hline D & C & 0 & 7.33 & 4.05 & 178 & 3 & 13 & 29.6865 & 67325 \\
\hline D & C & 0 & 4.29 & 4.05 & 178 & 4 & 31 & 17.3745 & 12244 \\
\hline D & C & 0 & 6.6 & 4.05 & 178 & 5 & 33 & 26.73 & 86366 \\
\hline D & C & 0 & 8.09 & 4.05 & 178 & 6 & 1 & 32.7645 & 100480 \\
\hline D & $\mathrm{C}$ & 0 & 6.74 & 4.05 & 178 & 7 & 45 & 27.297 & 124498 \\
\hline D & V & $N$ & 4.93 & 4.05 & 178 & 1 & 49 & 19.9665 & 58953 \\
\hline D & v & $\mathrm{N}$ & 3.32 & 4.05 & 178 & 2 & 14 & 13.446 & 22954 \\
\hline D & v & $N$ & 6.63 & 4.05 & 178 & 3 & 52 & 26.8515 & 39552 \\
\hline D & v & $N$ & 4.92 & 4.05 & 178 & 4 & 23 & 19.926 & 35473 \\
\hline D & V & $\mathrm{N}$ & 7.37 & 4.05 & 178 & 5 & 20 & 29.8485 & 69757 \\
\hline $\mathrm{D}$ & v & $\mathrm{N}$ & 6.72 & 4.05 & 178 & 6 & 5 & 27.216 & 126784 \\
\hline$D$ & v & $N$ & & 4.05 & 178 & 7 & & & \\
\hline$D$ & v & $\mathrm{N}$ & 8.68 & 4.05 & 178 & 1 & 54 & 35.154 & 31133 \\
\hline $\mathrm{D}$ & C & $\mathrm{N}$ & 7.92 & 4.05 & 178 & 2 & 8 & 32.076 & 75952 \\
\hline$D$ & C & $\mathrm{N}$ & 4.85 & 4.05 & 178 & 3 & 22 & 19.6425 & 54216 \\
\hline D & $\mathrm{C}$ & $N$ & 6.95 & 4.05 & 178 & 4 & 16 & 28.1475 & 721126 \\
\hline$D$ & C & $\mathrm{N}$ & 5.64 & 4.05 & 178 & 5 & 42 & 22.842 & 28045 \\
\hline D & $\mathrm{C}$ & $\mathbf{N}$ & 9.22 & 4.05 & 178 & 6 & 11 & 37.341 & 22954 \\
\hline D & $\mathrm{C}$ & $\mathrm{N}$ & & 4.05 & 178 & 7 & & & \\
\hline$E$ & V & 0 & 7.76 & 4.3 & 153 & 1 & 21 & 33.368 & 21597 \\
\hline $\bar{E}$ & V & 0 & 7.93 & 4.3 & 153 & 2 & 43 & 34.099 & 62731 \\
\hline $\mathrm{E}$ & V & 0 & 5.67 & 4.3 & 153 & 3 & 31 & 24.381 & 60304 \\
\hline$E$ & v & 0 & 7.22 & 4.3 & 153 & 4 & 25 & 31.046 & 72464 \\
\hline $\bar{E}$ & v & 0 & 6.79 & 4.3 & 153 & 5 & 41 & 29.197 & 162176 \\
\hline $\mathrm{E}$ & $v$ & 0 & 6.77 & 4.3 & 153 & 6 & 45 & 29.111 & 63037 \\
\hline$E$ & V & 0 & 7.3 & 4.3 & 153 & 7 & 49 & 31.39 & 79817 \\
\hline $\bar{E}$ & C & 0 & 7.08 & 4.3 & 153 & 1 & 33 & 30.487 & 77422 \\
\hline $\mathrm{E}$ & $\mathrm{C}$ & 0 & 7.07 & 4.3 & 153 & 2 & 5 & 30.401 & 34058 \\
\hline $\mathrm{E}$ & C & 0 & & 4.3 & 153 & 3 & 18 & & \\
\hline$E$ & C & 0 & 5.15 & 4.3 & 153 & 4 & 52 & 22.145 & 107075 \\
\hline $\bar{E}$ & C & 0 & 8 & 4.3 & 153 & 5 & 7 & 34.4 & 52616 \\
\hline$E$ & C & 0 & 6.56 & 4.3 & 153 & 6 & 1 & 28.208 & 216722 \\
\hline $\bar{E}$ & C & 0 & 9.98 & 4.3 & 153 & 7 & 4 & 42.914 & 46260 \\
\hline $\bar{E}$ & v & 0 & 5.99 & 4.3 & 153 & 1 & 27 & 25.757 & 100416 \\
\hline$E$ & v & 0 & & 4.3 & 153 & 2 & 24 & & \\
\hline$E$ & $v$ & 0 & 5.18 & 4.3 & 153 & 3 & 51 & 22.274 & 58488 \\
\hline$E$ & v & o & 6.83 & 4.3 & 153 & 4 & 32 & 29.369 & 32453 \\
\hline$E$ & $v$ & 0 & 4.85 & 4.3 & 153 & 5 & 40 & 20.855 & 91652 \\
\hline $\bar{E}$ & v & 0 & 5.45 & 4.3 & 153 & 6 & 13 & 23.435 & 43711 \\
\hline $\mathrm{E}$ & $v$ & 0 & 7.21 & 4.3 & 153 & 7 & 37 & 31.003 & 21647 \\
\hline$\vec{E}$ & C & 0 & 4.26 & 4.3 & 153 & 1 & 11 & 18.318 & 56346 \\
\hline $\bar{E}$ & C & 0 & 6.33 & 4.3 & 153 & 2 & 19 & 27.219 & 28135 \\
\hline $\mathrm{E}$ & c & 0 & 4.9 & 4.3 & 153 & 3 & 53 & 21.07 & 36214 \\
\hline$E$ & c & 0 & 5.7 & 4.3 & 153 & 4 & 54 & 24.51 & 162742 \\
\hline $\bar{E}$ & C & 0 & 7.15 & 4.3 & 153 & 5 & 34 & 30.745 & 150908 \\
\hline $\mathrm{E}$ & C & 0 & 5.63 & 4.3 & 153 & 6 & 23 & 24.209 & 89609 \\
\hline E & C & 0 & 5.03 & 4.3 & 153 & 7 & 50 & 21.629 & 173652 \\
\hline
\end{tabular}


Table V. Three-way ANOVA results for debonding strength/crack initiation strength.

\begin{tabular}{llllll}
\hline Source of variation & Df & SS & MS & F & P \\
\hline Type of Metal & 1 & 32.67 & 32.67 & 1.22 & .275 \\
Type of Ceramic & 1 & 32.58 & 32.58 & 1.22 & .276 \\
Opaque/non-opaque & 1 & 138.18 & 138.18 & 5.16 & .028 \\
Type of Metal x Type of Ceramic & 1 & 42.15 & 42.15 & 11.57 & .216 \\
Type of Metal x Opaque/non-opaque & 1 & 110.59 & 110.58 & 4.13 & .048 \\
Type of Ceramic x Opaque/non-opaque & 1 & 8.87 & 8.87 & 0.33 & .568 \\
Type of Metal x Opaque/non-opaque x & 1 & 57.12 & 57.12 & 2.13 & .151 \\
Type of Ceramic & & & & & \\
Residual & 44 & 1178.05 & 26.77 & & \\
Total & 51 & 1591.52 & 31.21 & & \\
\hline
\end{tabular}

$D f$, Degree of freedom; $S S$, sum of squares; $M S$, mean square. 
Table VI. Ra Values $(\AA)$ and debonding strength/crack initiation strength values (MPa) for each alloy and system

\begin{tabular}{|c|c|c|c|c|c|c|c|}
\hline $\begin{array}{l}\text { Specimen } \\
\text { no. }\end{array}$ & $\operatorname{Ra}(\AA)$ & System & $\begin{array}{l}\text { Debond. } \\
\text { Str. } \\
\text { (MPa) }\end{array}$ & $\begin{array}{c}\text { Specimen } \\
\text { no. }\end{array}$ & $\operatorname{Ra}(\AA)$ & System & $\begin{array}{l}\text { Debond. } \\
\text { Str } \\
\text { (MPa) }\end{array}$ \\
\hline $\begin{array}{c}1 \\
3 \\
5 \\
8 \\
9 \\
11 \\
13 \\
14 \\
15 \\
16 \\
19 \\
20 \\
22 \\
23 \\
24 \\
26 \\
27 \\
30 \\
31 \\
33 \\
41 \\
42 \\
45 \\
49 \\
51 \\
52 \\
54 \\
56\end{array}$ & $\begin{array}{c}100480 \\
40646 \\
126784 \\
75972 \\
43991 \\
22954 \\
67325 \\
22954 \\
41322 \\
72126 \\
66137 \\
69757 \\
54216 \\
35473 \\
50857 \\
47342 \\
62512 \\
39674 \\
112244 \\
86366 \\
33730 \\
28045 \\
124498 \\
58953 \\
62769 \\
39552 \\
31133 \\
32655\end{array}$ & $\begin{array}{l}\text { DOC } \\
\text { DOV } \\
\text { DNV } \\
\text { DNC } \\
\text { DOV } \\
\text { DNC } \\
\text { DOC } \\
\text { DNV } \\
\text { DOV } \\
\text { DCN } \\
\text { DCN } \\
\text { DNV } \\
\text { DCN } \\
\text { DNV } \\
\text { DOV } \\
\text { DNV } \\
\text { DOV } \\
\text { DOC } \\
\text { DOC } \\
\text { DOC } \\
\text { DOV } \\
\text { DCN } \\
\text { DOC } \\
\text { DNV } \\
\text { DOC } \\
\text { DNV } \\
\text { DNC } \\
\text { DOV }\end{array}$ & $\begin{array}{c}32.7645 \\
21.708 \\
27.216 \\
32.076 \\
23.733 \\
37.341 \\
29.6865 \\
13.446 \\
26.973 \\
28.1475 \\
\\
29.8485 \\
19.6425 \\
19.926 \\
21.0195 \\
\\
26.9325 \\
23.4495 \\
17.3745 \\
26.73 \\
30.0915 \\
22.842 \\
27.297 \\
19.9665 \\
28.998 \\
26.8515 \\
35.154 \\
36.6025\end{array}$ & $\begin{array}{l}1 \\
4 \\
5 \\
7 \\
11 \\
13 \\
18 \\
19 \\
21 \\
23 \\
24 \\
25 \\
27 \\
31 \\
32 \\
33 \\
34 \\
37 \\
40 \\
41 \\
43 \\
45 \\
49 \\
50 \\
51 \\
52 \\
53 \\
54\end{array}$ & $\begin{array}{c}216722 \\
46260 \\
34058 \\
52616 \\
56346 \\
43711 \\
92100 \\
28135 \\
21597 \\
89609 \\
121336 \\
72464 \\
100416 \\
60304 \\
32453 \\
77422 \\
150908 \\
21647 \\
91652 \\
162176 \\
62731 \\
63037 \\
79817 \\
173652 \\
58488 \\
107075 \\
36214 \\
162742\end{array}$ & $\begin{array}{l}\text { EOC } \\
\text { EOC } \\
\text { EOC } \\
\text { EOC } \\
\text { ENC } \\
\text { ENV } \\
\text { EOC } \\
\text { ENC } \\
\text { EOV } \\
\text { ENC } \\
\text { ENV } \\
\text { EOV } \\
\text { ENV } \\
\text { EOV } \\
\text { ENV } \\
\text { EOC } \\
\text { ENC } \\
\text { ENV } \\
\text { ENV } \\
\text { EOV } \\
\text { EOV } \\
\text { EOV } \\
\text { EOV } \\
\text { ENC } \\
\text { ENV } \\
\text { EOC } \\
\text { ENC } \\
\text { ENC }\end{array}$ & $\begin{array}{c}28.208 \\
42.914 \\
30.401 \\
34.4 \\
18.318 \\
23.435 \\
\\
27.219 \\
33.368 \\
24.209 \\
\\
31.046 \\
25.757 \\
24.381 \\
29.369 \\
30.487 \\
30.745 \\
31.003 \\
20.855 \\
29.197 \\
34.099 \\
29.111 \\
31.39 \\
21.629 \\
22.274 \\
22.145 \\
21.07 \\
24.51\end{array}$ \\
\hline AVG. & 27446.21 & & & AVG. & 40626.10 & & \\
\hline
\end{tabular}


Table VII. Mean (SD) debonding strength/crack initiation strength values (MPa) for each metal-ceramic system:

\begin{tabular}{lcc}
\hline System & Mean Values & Statistical Comparison* \\
\hline EOC & $31.43(6.92)$ & $\mathrm{A}$ \\
EOV & $30.37(3.25)$ & $\mathrm{A}$ \\
DNC & $29.20(6.97)$ & $\mathrm{A}$ \\
DOC & $26.61(4.98)$ & $\mathrm{A}$ \\
DOV & $26.15(4.29)$ & $\mathrm{A}$ \\
ENV & $25.45(4.04)$ & $\mathrm{A}$ \\
ENC & $23.96(4.14)$ & $\mathrm{A}$ \\
DNV & $22.88(6.15)$ & $\mathrm{A}$ \\
\hline Identical upper-case letters denote no significant differences in metal-ceramic \\
system (P>.05).
\end{tabular}


Table VIII. Mean (SD) debonding strength/crack initiation strength values (MPa) for each metal and opaque/non-opaque system, irrespective of type of porcelain.

\begin{tabular}{llc}
\hline System & Mean Value & Statistical Comparison* $^{*}$ \\
\hline EO & $30.89(5.19)$ & $\mathrm{A}$ \\
DO & $26.38(5.17)$ & $\mathrm{AB}$ \\
DN & $26.04(5.17)$ & $\mathrm{AB}$ \\
EN & $24.79(5.19)$ & $\mathrm{B}$ \\
\hline Identical upper-case letters denote no significant differences among metal and opaque/non- \\
opaque systems (P>.05).
\end{tabular}


Graph 1. K value determinant from ISO 9693: 1999 (E)

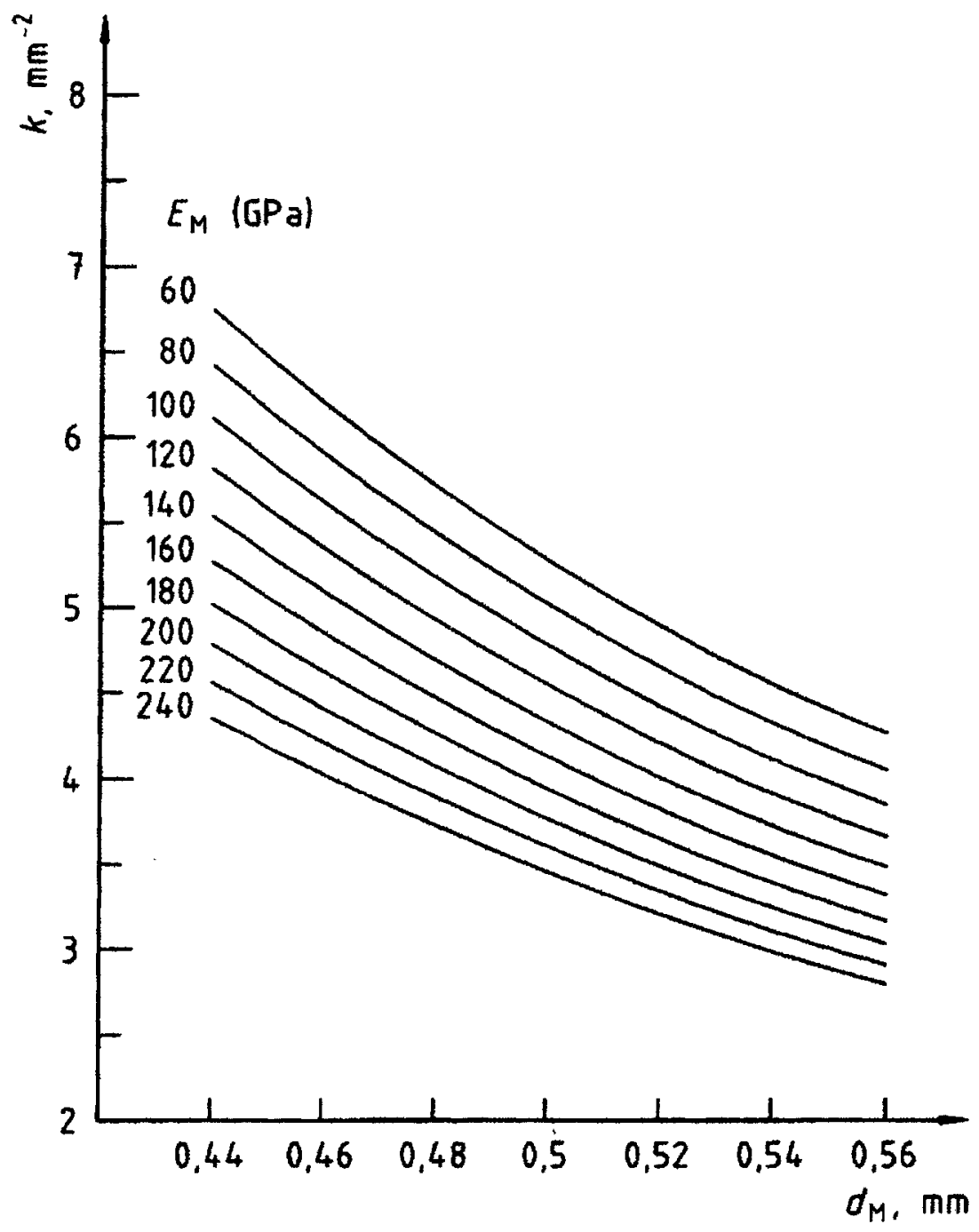


Graph 2. Mean (SD) debonding strength/crack initiation strength values for each metal-ceramic system.

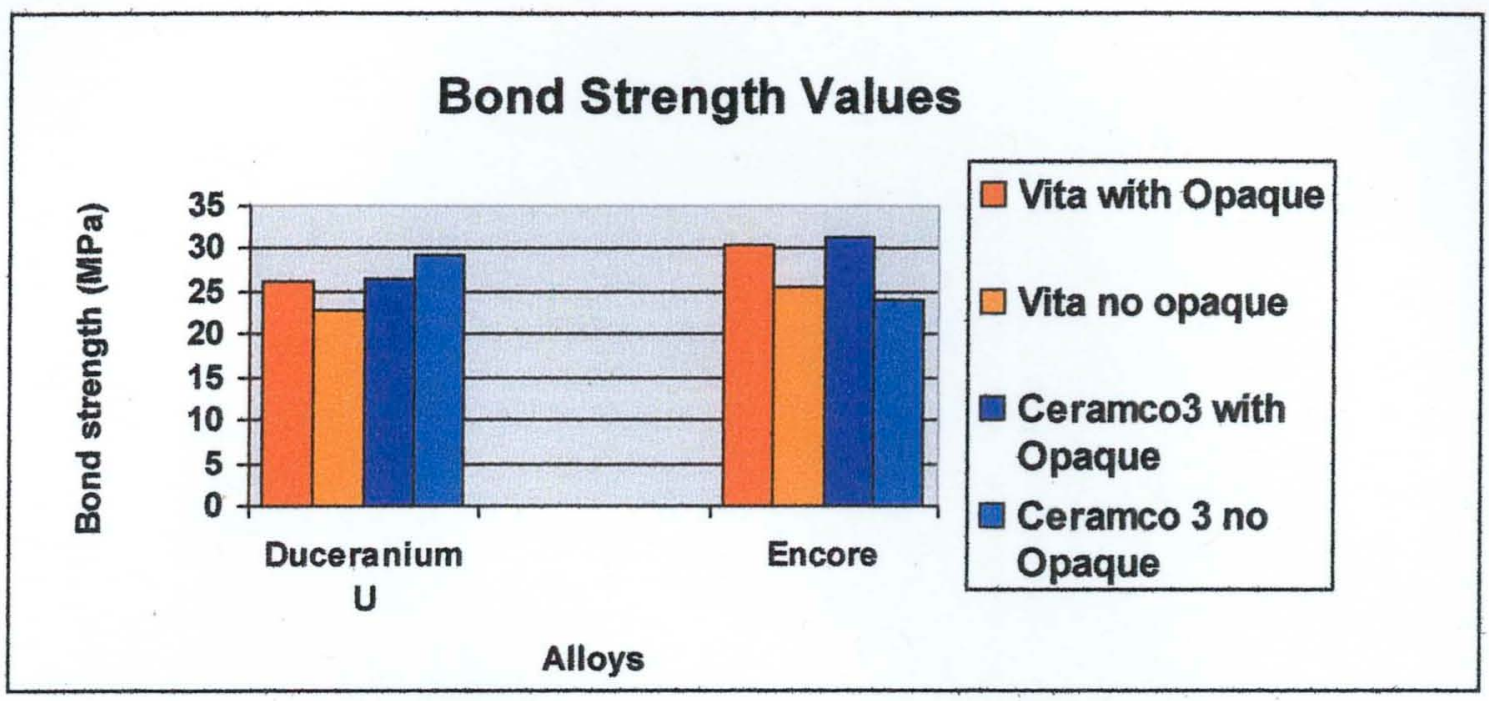


Graph 3. Dispersion of Specimen Values, Bonding Strength (MPa) by Ra (̊̊)

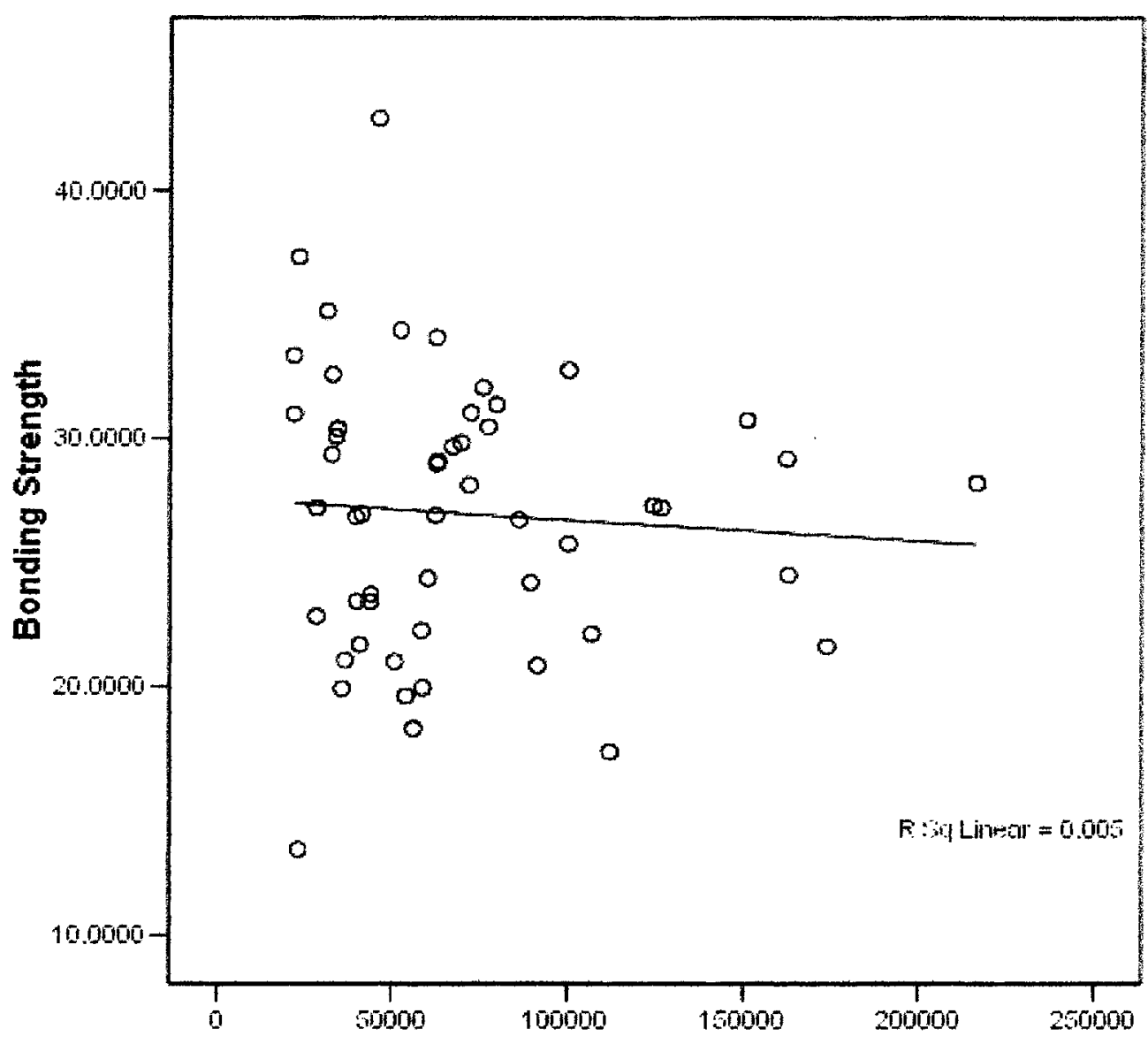

$\mathbf{R a}$ 